\title{
Exploration of room acoustics coupling in Hagia Sophia of İstanbul for its different states
}

Zühre Sü Gül

Citation: The Journal of the Acoustical Society of America 149, 320 (2021); doi: 10.1121/10.0002971

View online: https://doi.org/10.1121/10.0002971

View Table of Contents: https://asa.scitation.org/toc/jas/149/1

Published by the Acoustical Society of America

\section{ARTICLES YOU MAY BE INTERESTED IN}

Seabed type and source parameters predictions using ship spectrograms in convolutional neural networks

The Journal of the Acoustical Society of America 149, 1198 (2021); https://doi.org/10.1121/10.0003502

Acoustic differences between voiced and whispered speech in gender diverse speakers

The Journal of the Acoustical Society of America 148, 4002 (2020); https://doi.org/10.1121/10.0002952

Machine learning in acoustics: Theory and applications

The Journal of the Acoustical Society of America 146, 3590 (2019); https://doi.org/10.1121/1.5133944

Two-dimensional exterior sound field reproduction using two rigid circular loudspeaker arrays

The Journal of the Acoustical Society of America 148, 2236 (2020); https://doi.org/10.1121/10.0002280

Auditory perception stability evaluation comparing binaural and loudspeaker Ambisonic presentations of dynamic virtual concert auralizations

The Journal of the Acoustical Society of America 149, 246 (2021); https://doi.org/10.1121/10.0002942

Feit's seminal article on radiation of sound by a vibrating plate

The Journal of the Acoustical Society of America 149, R1 (2021); https://doi.org/10.1121/10.0002422

\section{Advance your science and career as a member of the}




\title{
Exploration of room acoustics coupling in Hagia Sophia of Istanbul for its different states
}

\author{
Zühre Sü Güla) \\ Department of Architecture, Bilkent University, 06800, Ankara, Turkey
}

\begin{abstract}
:
İstanbul's Hagia Sophia is a monumental structure with multiple sub-spaces coupled to one another through arches. Its architectural elements have undergone alterations as its function has changed from that of a church to a mosque, a mosque to a museum, and back to a mosque. This study makes use of Hagia Sophia's rich formal and material characteristics to conduct a comprehensive investigation of room acoustics coupling. The methodology involves the application of the diffusion equation model (DEM) for sound energy flow analysis. Energy flow decays and energy flow dips are examined for almost 1000 receiver positions distributed throughout the various sub-spaces of the building. Ray-tracing (Ray-t) simulations are used to support the energy flow decay analysis conducted using DEM. The Ray-t data are subjected to Bayesian analysis to identify the decay parameters and the degree of acoustical coupling. Among the many variables, the source-receiver distance and positioning within different sub-spaces appear to be the underlying determinant of multi-slope sound decay pattern. On the other hand, the cases of multi-slope decays identified within the structure tend to weaken and single-slope cases increase when the overall absorption area increases in the mosque state due to the carpeted floor. (c) 2021 Acoustical Society of America.

https://doi.org/10.1121/10.0002971

(Received 4 September 2020; revised 5 December 2020; accepted 7 December 2020; published online 12 January 2021)

[Editor: Ning Xiang]

Pages: 320-339
\end{abstract}

\section{INTRODUCTION}

The acoustics of historically significant sacred spaces has long attracted the interest of researchers seeking initially to identify and later to preserve their characteristic sound fields (Cirillo and Martellotta, 2005; Kleiner et al., 2010). Previous studies have focused on the sound field analysis of churches (Pedrero et al., 2014; Luigi and Martellotta 2015; Giron et al., 2017), basilicas (Martellotta, 2009; Martellotta, 2016), cathedrals (Suárez et al., 2015; Alvarez-Morales et al., 2016; Martellotta et al., 2018; Anderson and Anderson, 2000), and mosques (Abdelazeez et al., 1991; Abdou, 2003; Suárez et al., 2018; Sü and Y1lmazer, 2008; Sü Gül and Çalışkan, 2013a,b; Sü Gül et al., 2014). Research has also been conducted on the virtual reconstruction of sacred spaces with a view to archiving their intangible heritages and comprehending their architectural and acoustical evolution over time (Suárez et al., 2005, 2018; Alonso et al., 2018; D’Orazio et al., 2020).

Many Christian and Islamic worship spaces, especially those of monumental appearance and historical significance, are characterized by gigantic interior volumes. These are composed of multiple, interconnected sub-spaces covered by a central dome, sub-domes, or vaults. These specific architectural tectonics have the potential of multi-slope sound energy decay formation similar to that observed in coupled-volume spaces (Sü, 2006; Pu et al., 2011; Meissner, 2012; Xiang et al., 2013; Xiang et al., 2018). The multi-slope (i.e., non-

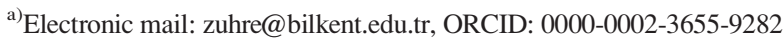

exponential) sound energy decay formation in the coupled volumes of sacred sites is a significant topic of ongoing research. The literature contains detailed descriptions and discussion of particular sound fields with multiple decay rates in various worship spaces including churches (Magrini and Magnani, 2005; Chu and Maka, 2009), basilicas (Raes and Sacerdote, 1953; Martellotta, 2009, 2016), cathedrals (Anderson and Anderson, 2000; Martellotta et al., 2018), and mosques (Sü Gül et al., 2016; Sü Gül et al., 2017).

The methods of data collection and analysis employed in these studies include field tests, scale modelling, and acoustical simulations. These methods suffice to obtain the impulse responses recorded in, or simulated for, a building. Further in-depth analysis is needed to estimate and analyze the sound fields of coupled-volume systems, where the probability of multi-slope sound energy decay is high. State-ofthe-art non-exponential energy decay investigations in coupled volume spaces employ various models that have their roots in statistical theory (Eyring, 1931; Cremer and Muller, 1978), wave theory (Harris and Feshbach, 1950; Meissner, 2007, 2012), statistical energy analysis (Wester and Mace, 1998; Anderson and Anderson, 2000; Martellotta, 2009), further, geometrical acoustics (Nijs et al., 2002; Summers et al., 2004; Summers et al., 2005), and diffusion equation modeling (DEM) (Billon et al., 2006; Jing and Xiang, 2008a; Xiang et al., 2009; Luizard et al., 2014; Sü Gül et al., 2017).

The present study concerns Hagia Sophia, one of the most significant monuments of the Historic Areas of Istanbul World Heritage Site, and a building of great 
importance for different religions. Hagia Sophia's rich visual and aural aesthetics has been a source of inspiration for researchers regarding its touch upon art history, architecture, and acoustics (Pentcheva, 2011). At different times, Hagia Sophia has been used as a church, a mosque, and a museum. It was recently re-converted to function as a mosque. Previous research on Hagia Sophia includes multislope decay analysis (Sü Gül et al., 2018) for the field configurations at the time of the measurements when Hagia Sophia was functioning as a museum, and a validation of the simulated DEM for a multi-domain solution (Sü Gül et al., 2019). According to field tests, Hagia Sophia possesses a variety of aural experiences (Sü Gül et al., 2018), including both single and multiple sound energy decays.

The aim of this study is to conduct a comprehensive study over the whole interior space of Hagia Sophia that has the potential of multi-rate energy decay formation in relation to its complex formal identity, which could not have been measured in field tests due to practical limitations. The results are discussed in terms of the changes in the function of the building as well as the way in which the sound energy decay pattern (multi-rate or single) relates to geometry, the volumes of the spaces, the apertures (arches), and the source-receiver distances. By presenting the results of a comprehensive analysis of architectural and acoustical variables in relation to multi-slope sound energy decay, this study also aims to guide possible future applications of coupled-room designs in architectural acoustics. These analyses can also further inspire auralization studies, held previously for Hagia Sophia, that rely on the impulse responses synthesized over the balloon pops, for additional receiver positions where multi-slope energy decay is observed (Abel et al., 2010; Abel et al., 2013).

This study primarily applies DEM using a multi-domain solution in a finite-element medium. As previously demonstrated (Sü Gül et al., 2019), the multi-domain solution approach has been found to be much more reliable for this structure than the single-domain diffusion model approach. Subsequently, DEM, ray-tracing (Ray-t), and Bayesian analysis are all used to investigate the room acoustics coupling for unmeasured receiver positions within the whole volume for both museum and mosque state. In the investigation of multislope sound energy decays, the selection of the proper model is critical. This study applies Bayesian probabilistic inference in order to quantify the decay parameters of multi-sound energy decays. This approach has proved to be efficient for estimating key characteristics of multiple-slope sound energy decays (Jasa and Xiang, 2009, 2012; Xiang et al., 2011).

This paper is structured as follows. Section II sets out the historical and architectural features of Hagia Sophia. Section III gives details of the methodologies used for collecting and analyzing the data, including in situ (field) tests, DEM equations and their numerical implementation, Ray- $t$ model implementation and calibration, and Bayesian decay parameter estimates. In Sec. IV, the results are discussed in detail. Section V concludes the paper by emphasizing the major findings.

\section{HISTORICAL AND ARCHITECTURAL DESCRIPTION OF HAGIA SOPHIA IN ISTANBUL}

Hagia Sophia is not only a masterpiece of Byzantine art but a significant element of the world's historical heritage. It was constructed in Constantinople (Istanbul) as a church between the years 532 and 537, during the reign of the Byzantine Emperor Justinian. After the Ottoman conquest of 1453, during the rule of Mehmet II, it was converted from a church to a mosque. In 1934, upon an order from Atatürk, Hagia Sophia was converted to a museum (Mark and Çakmak, 1992). Very recently (July 24, 2020), the building has once again begun to function as a mosque.

In the almost 1.5 millennia of its existence, Hagia Sophia has suffered much damage, mostly due to major earthquakes. It has undergone various phases of structural repair and reinforcement. The alterations and interventions that have occurred as a result of the repairs and restoration work have been discussed in detail in a previous study (Sü Gül, 2019). The conversion of the building from a church to a mosque entailed the concealment of some Christian elements and the addition of some Islamic ones. Among the Islamic additions in the interior space, a mihrab was added on the kiblah axis. The minbar was constructed in the same direction. Prayer mats and banners of victory were hung on the walls. A mahfil was placed for use by the müezzin. The Imperial Pavilion and Imperial Loge were added. Since pictorial representations are traditionally not permitted in Islam, the mosaics were gradually covered up, whitewashed, or plastered over and consequently preserved (Kahler and Mango, 1967). In 1847, all the surviving mosaics were uncovered and copied in order to ensure a visual record. In 1992, when the Hagia Sophia was in use as a museum, major restoration and consolidation work was carried out on the mosaics in the dome in collaboration with, and with the support of UNESCO (Oyhon and Etingü, 1999). Meanwhile, the carpets on the floor were removed. When, very recently, the building started to function as a mosque again, the floors of the main prayer zone, or naos, were once again covered with carpets and the frescos exposed to the prayer hall were masked with curtains.

In architectural terms, Hagia Sophia is an expanded dome basilica: a rectangular building covered by a central dome situated between two half domes that integrates longitudinal and centralized planning. The structure has an approximate width of $70 \mathrm{~m}$. The length of the entire interior from the exonarthex to the edge of the apse is $92 \mathrm{~m}$. The central nave is built on an east-west axis. The central dome rises $55 \mathrm{~m}$ above the paving of the nave. Today, the dome is not exactly round but slightly elliptical, with a diameter of $31.2 \mathrm{~m}$ on one axis and $32.8 \mathrm{~m}$ on the other (Oyhon and Etingü, 1999). The domed central space is skirted by two large hemicycles covered by half-domes to the east and west. The side aisles are separated from the central nave by columns and arches and sheltered under vaults. Above the side aisles and the inner narthex, there are galleries that form a U-shape.

Hagia Sophia has an approximate interior volume of $150000 \mathrm{~m}^{3}$. This creates an outstanding visual and 
acoustical environment. The opportunity to study the interior sound field of such a majestic building with so many coupled sub-spaces is very inspiring. At the same time, the sound field has changed continuously during the life span of the building due to the changes in the pattern of activity. The architectural adaptation of worship spaces to meet the needs of different religions has also been observed to alter their sonic environments in other sacred sites (Suárez, 2005).

The interior sound field of Hagia Sophia has previously been described through the investigation of sound energy flow vectors (Sü Gül et al., 2019). This previous study focused on the building in its museum state and a limited number of source and receiver positions (in situ tests). It proved that a diffusion model for a multi-domain solution could be reliably employed in multi-rate sound energy decay analysis. The present study extends the multi-rate analysis conducted within that immense volume to almost a thousand positions, which it would not be practical to test, including different elevations, and to the mosque scenario with its carpeted floor, with a view to understanding the parameters affecting sound propagation in acoustically coupled volumes contained and unified within an immense structure. This in-depth multi-rate sound energy decay investigation makes use of a variety of methods as detailed in the following section.

\section{METHODOLOGY}

The principal methods used in this study are the DEM method for investigating sound energy flow dips, and Ray- $t$ simulations for further investigation of multi-slope decay parameter estimates within a Bayesian framework (Xiang et al., 2011). Data previously obtained from the earlier in situ tests are used for the calibration of the acoustical models employed in the simulations.

\section{A. In situ tests}

In a previous study, acoustical field tests were conducted in Hagia Sophia (Sü Gül et al., 2018). The tests were held on 25 August 2014, on the ground floor, when the building was unoccupied. In accordance with ISO 3382-1:2009 (ISO, 2009), a B\&K (type 4292-L) standard dodecahedron omnipower sound source was used for acoustical signal generation with a B\&K (type 2734-A) power amplifier. The impulse responses at the various measurement points were captured by a B\&K (Type 4190ZC-0032) microphone incorporated into a $\mathrm{B} \& \mathrm{~K}$ (type $2250-\mathrm{A}$ ) hand-held analyzer. The sampling frequency of the recorded multi-spectrum impulse was $48 \mathrm{kHz}$, and the interval of interest was between 100 and $8000 \mathrm{~Hz}$. DIRAC Room Acoustics Software (type 7841 v.4.1) was used to generate different noise signals. In order to be able to make reliable decay parameter estimates, it was aimed to obtain a signal that was at least $45-50 \mathrm{~dB}$ higher than the noise in all octaves. The signals tested were E-sweep, MLS, MLS-pink, balloon pop, and wood clap. Up to five pre-averages were applied over multiple measurements, with an impulse response length of $21.8 \mathrm{~s}$. Since E-sweep provided the highest peak-to-noise ratio (PNR) values, the results from these samples were utilized in postprocessing. Three sources (by the mahfil and in front of the altar, $\mathrm{S} 1$; in a corner side aisle, S2; and underneath the central dome, S3) and six receiver positions were tested in numerous configurations within the limited time span permitted by the museum at the time. The source and receiver locations were selected not only to reflect positions of significance in the different religious uses of the building but also to examine possible multi-rate decay patterns. Thus, the first source position (S1) represents a typical position in the sacred use of the space, while the second, corner position (S2) was chosen with a view to exciting the space from an asymmetric location so as to be able to investigate different decay patterns.

\section{B. DEM}

As discussed in previous literature (Ollendorff, 1969; Picaut et al., 1997; Valeau et al., 2006; Visentin et al., 2012), the DEM method is based on the assumptions that particles travel along straight lines at the speed of sound in the interior space and that multiple diffuse reflections occur at the room boundaries which can be conceived of as scattering objects. The sound radiation is treated in a similar way to electromagnetic radiation. For the DEM method to be valid in room acoustics scenarios, the density of the scattering sound particles must be high, and the reflection of energy must dominate over absorption in the space under investigation (Navarro et al., 2010). Hagia Sophia's interior surfaces are fragmented by architectural elements and the majority of the interior surfaces are highly reflective. In this study, the DEM method is essentially used to identify energy flow decays and energy flow dips in the search for a multi-slope decay pattern in Hagia Sophia. The equations used are as follows.

The sound energy flow vector $J$ caused by the gradient of the sound energy density $w$ at position $(r)$, and time $(t)$ can be expressed by Fick's law (Ollendorff, 1969; Visentin et al., 2012),

$$
J(r, t)=-D \nabla w(r, t)
$$

where $D$ is the diffusion coefficient, which takes into account the room morphology via its mean free path (MFP) ( $\lambda$ ), given by (Valeau et al., 2006)

$$
D=\frac{\lambda c}{3}=\frac{4 V c}{3 S}
$$

where $V$ is the volume of the room, $c$ is the speed of sound, and $S$ is the total surface area of the room.

The time-dependent sound energy density $w$ in a unit time ( $\mathrm{t}$ ) and position ( $\mathrm{r}$ ), in the presence of an omnidirectional sound source, $q(r, t)$ can be estimated by

$$
\frac{\partial w(r, t)}{\partial t}-D \nabla^{2} w(r, t)=q(r, t), \in V
$$

In Eq. (3), the source term $q(r, t)$ is zero for any sub-domain in which no source is present. Physically, the sound source, 
which is a point source, is turned on for a sufficiently long period of time to establish steady-state field conditions and is then switched off at a time point referred to as $0 \mathrm{~s}$ (Xiang et al., 2009). The numerical implementation requires a timedependent solution already before $t=0 \mathrm{~s}$ in order to ensure the system arrives at the steady state. The energy flow level is then defined as (Jing and Xiang, 2008b)

$$
\begin{aligned}
J_{L}(r, t)= & 10 \log _{10}\left\{\left[\frac{\partial w(r, t)}{\partial x}\right]^{2}+\left[\frac{\partial w(r, t)}{\partial y}\right]^{2}\right. \\
& \left.+\left[\frac{\partial w(r, t)}{\partial z}\right]^{2}\right\} .
\end{aligned}
$$

It should be noted that $J_{L}$ in Eq. (4) gives the sound-energy flow level, whereas $J$ as given in Eq. (5) indicates the soundenergy flow vector for a specific location in space at a specific time. The effects of enclosing room surfaces for cases in which the sound energy in an enclosure/domain $(V)$ cannot escape from bounded surfaces $(S)$ is determined as

$$
J(r, t) \cdot n=-D \nabla w(r, t) \cdot n=A_{X} c w(r, t), \text { on } S,
$$

where $A_{x}$ is the modified absorption factor, with $A_{x}=\alpha /[4(1$ $-\alpha / 2)$ ]. It should be noted that the average absorption coefficient of overall interior surfaces of Hagia Sophia for $1 \mathrm{kHz}$ is 0.08 with marble floor and 0.12 with carpet floor. The condition with carpet meets DEM assumptions when the modified absorption factor is applied. The modified boundary condition suits situations when a diffuse field condition is satisfied by totally sound reflective interior surfaces, but as well applicable for rooms where a small portion of surfaces is moderately absorptive or one boundary absorbs a portion of the sound energy (Jing and Xiang, 2008).

The resulting system boundary equation is as follows (Jing and Xiang, 2008a):

$$
-D \frac{\partial w(r, t)}{\partial n}=\frac{c \alpha}{4(1-\alpha / 2)} w(r, t), \text { on } S,
$$

where $\alpha$ is the absorption coefficient of the specific surface or boundary. Another boundary condition is the continuous boundary of the coupling aperture, applied in multi-domain solutions, which has to fulfill the following condition (Xiang et al., 2013):

$$
\hat{n} \cdot\left[D_{1} \nabla w\left(r_{b}, t\right)-D_{2} \nabla w\left(r_{b}, t\right)\right]=0 .
$$

This represents a continuity boundary condition for interior boundaries at the aperture position $r_{b}$, where $D_{1}$ is the diffusion coefficient in the primary room and $D_{2}$ is the diffusion coefficient for the secondary room. For two rooms with proportionate dimensions, $D_{i}=\lambda_{i} c / 3$, with $\lambda_{i}$ being the MFP of the individual rooms.

\section{Bayesian decay parameter estimates}

The computational analysis methodology of this study employs Bayesian probabilistic inference, which is a quantitative theory of inference that includes valid rules of statistics for relating and manipulating probabilities. Bayesian analysis has recently been applied in several studies, and reliable methods of characterizing sound energy decays consisting of one, two, or more slopes have been presented (Jasa and Xiang, 2009, 2012; Xiang et al., 2011).

In the process of Bayesian analysis, room impulse responses (RIR) are first collected through either field tests or simulations. These RIRs are then used to generate Bayesian model-based parameter estimates which determine the parameters of the decay profile, namely, the "slopes of decay" and the "ordinate intercepts" of these slopes. The parametric model given in Eq. (8) describes the Schroeder decay function and contains decay parameters of $A_{j}$ and $T_{j}$, where $A_{j}$ is the linear amplitude parameter and is related to the level of individual exponential decay terms, $T_{j}$ is the decay time associated with the logarithmic decay slope of individual exponential decay terms, with $j=1,2, \ldots, S$, and $S$ is the maximum number of exponential decay terms, also termed the decay order, $A_{0}\left(t_{K}-t i\right)$ is the noise term, and $t_{K}$ is the upper limit of integration, where the subscript $K$ is the total number of data points and $t_{i}$ with a lower-case subscript $i$ represents the discrete time variable (Xiang et al., 2011)

$$
H_{\mathrm{s}}\left(\mathrm{A}, \mathrm{T}, t_{i}\right)=A_{0}\left(t_{K}-t_{i}\right)+\sum_{j=1}^{S} A_{j}\left(e^{-13.8 t_{i} / T_{j}}-e^{-13.8 t_{K} / T_{j}}\right)
$$

where index $0 \leq i \leq K-1$.

In estimating the probable number of decay slopes, the quantifier Bayesian information criterion (BIC) is used as proposed by Xiang et al. (2011). Implementing the principles of parsimony and Ockham's razor, Bayesian evidence prefers simpler models and penalizes over-fitting. It therefore offers effective tools for model selection and comparison, going beyond traditional parameter estimation methods. When selecting from among a set of decay models in the course of an energy decay analysis, the model yielding the highest BIC value is considered to be the most concise model providing the best fit to the decay function data and at the same time capturing the important exponentially decaying features evident in the data.

\section{Model implementation and calibration for DEM and Ray-t}

The acoustical model of Hagia Sophia is generated on the basis of the latest building survey registers (röleve) provided by the Turkish Ministry of Culture and TourismGeneral Directorate of Turkish Cultural Heritage. In order to minimize discrepancies between the findings, the same acoustical model is utilized both for DEM and for Ray-t. The solid model used for the DEM solution is converted to a model composed of three-dimensional (3D) faces for import to Ray-t. The Ray-t simulations are carried out on ODEON Room Acoustics Software v.14.04 (Odeon A/S, Lyngby, Denmark) (Naylor, 1993), which is a combined model of the 
image source method and Ray-t. In the Ray-t simulations, up to 1000000 rays are tested in order to ensure the inclusion of sufficient numbers of rays reaching the farthest locations, while the maximum reflection order is set to 10000 . As no significant difference in outcomes is observed for numbers of rays between 250000 and 10000000,250000 rays are used to simulate all the receiver positions for greater efficiency in terms of computation time.

The DEM of Hagia Sophia is numerically implemented in a finite-element medium. The effect of the coupling of different sub-volumes is reflected using a multi-domain solution (Sü Gül et al., 2019), which has proved to be much more reliable for modeling Hagia Sophia's fragmented interior space. As highlighted in a previous study (Sü Gül et al., 2019), if the mean coupling factor (MCF) of two rooms that are connected with an aperture, arches in the case of Hagia Sophia, is smaller than 0.30 , the rooms or volumes can be treated as individual domains (sub-domain of the main structure) with their specific diffusion coefficient in a DEM computation. Accordingly, specific diffusion coefficients are defined for the sub-volumes (hereinafter sub-domains) in relation to their MFPs. The sub-domains are defined on the basis of architectural details. In Hagia Sophia, the narthex, aisles, and galleries (at balcony level), all sheltered under vaults of various styles, are connected to the main space, the naos or middle nave, by arches (coupling apertures) of different sizes. All are treated as individual domains. Mesh size is a critical parameter in finite-element solutions given considerations of computational speed. However, the DEM can be applied as long as the maximum mesh size is smaller than the MFP of the room. The geometrical model of Hagia Sophia has 691865 linear Lagrange-type mesh elements (Fig. 1, bottom). The mesh sizes range from $1 / 4$ to $1 / 14$ of MFP, satisfying the MFP criteria for the DEM.

Table I shows the volumes and total surface areas of the individual domains. The MFPs and diffusion coefficients (D) calculated for the different domains are also given. As in the field tests, omni-directional sound sources are used in the simulations. To calibrate the model, the field test results for two source positions and six receiver positions are compared to the simulation results for the same positions. A total of 980 additional receiver positions are distributed throughout the interior space to test the occurrence of multi-rate decay in relation to geometrical attributes including aperture sizes, the volumes, and shapes of the primary and secondary spaces of the structure.

Figure 1 shows the plan and a longitudinal section of Hagia Sophia (top and center) along with the mesh model (bottom). In the Appendix, the individual domain numbers and receiver positions are coded. Domain numbers D0 to D9 and receiver positions a to $\mathrm{d}$ indicate the main domain numbers and L1-L12 refer to different elevations $(\mathrm{L} 1=1.20 \mathrm{~m}$ above ground; L2 $=4.20 \mathrm{~m}$ above ground, and so on). For ease of comparison of the results using graphs, each domain is also divided into multiple groups. The first point of each of the vertical groups is indicated on the plan on Fig. 1 (center) and the group continues upwards to the highest level at

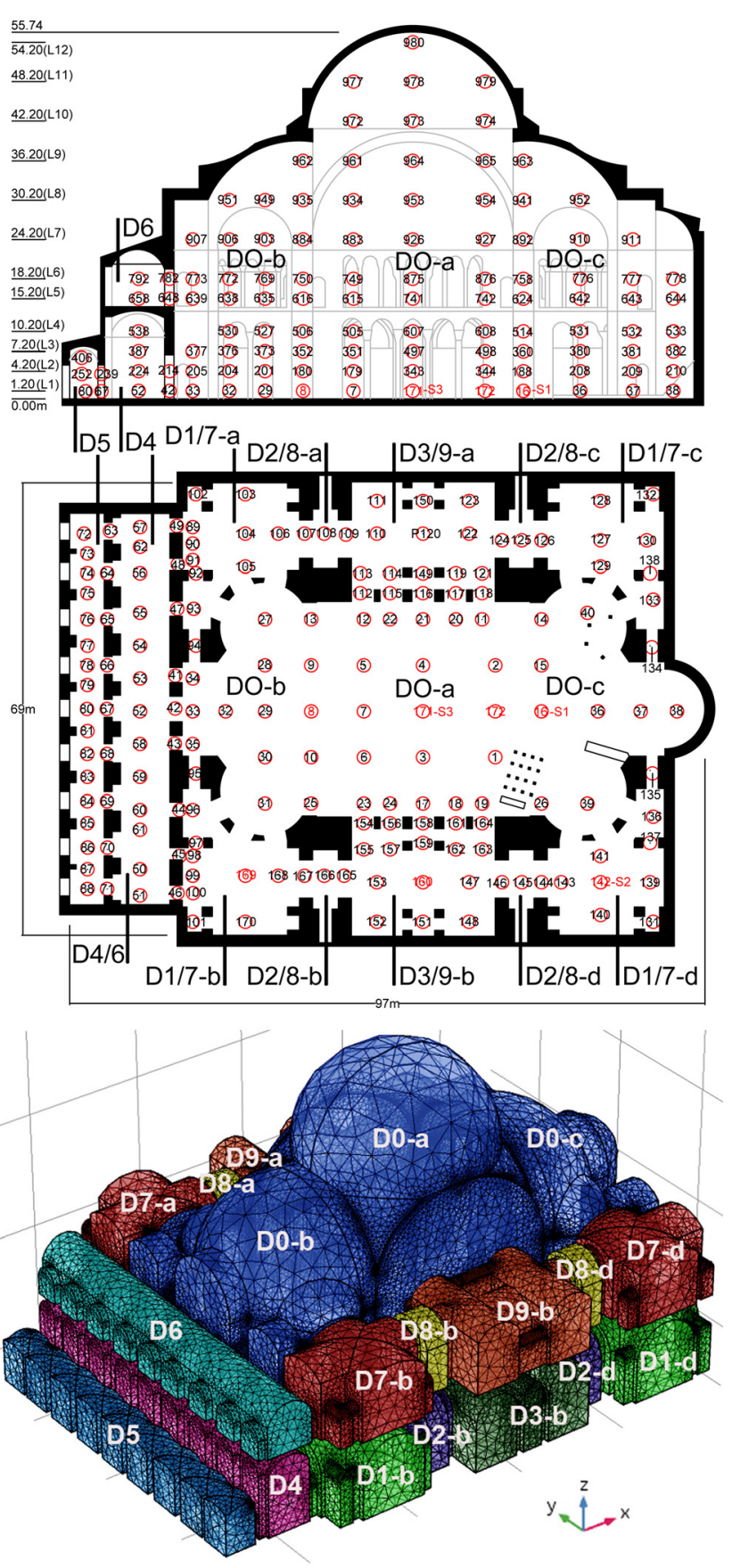

FIG. 1. (Color online) Hagia Sophia plan and longitudinal section views (top and center); mesh model with individual domain numbers (bottom).

that specific position on the plan. This provides a grouped grid distribution for receiver positions inside the entire space. On both the plan and the longitudinal section shown on the top and center of Fig. 1, the positions of the sources and receivers that were also tested during the field measurements are highlighted in red fonts.

The sound absorption coefficients of the interior surfaces are determined for each material by tuning the models to the existing field test results. In the process of calibrating the DEM and Ray-t models, the decay rates obtained from the field tests for receiver positions exhibiting single-slope characteristics are compared to the same receiver positions 
TABLE I. Volume $(V)$, surface area $(S)$, MFP, and diffusion coefficients (D) of individual domains.

\begin{tabular}{lrrrr}
\hline \hline & $V\left(\mathrm{~m}^{3}\right)$ & $S\left(\mathrm{~m}^{2}\right)$ & MFP $(\mathrm{m})$ & $D$ \\
\hline D0 & 95960 & 17647 & 21.8 & 2487 \\
D1 & 2575 & 1241 & 8.3 & 949 \\
D2 & 625 & 468 & 5.3 & 611 \\
D3 & 4430 & 2158 & 8.2 & 939 \\
D4 & 6771 & 3434 & 7.9 & 902 \\
D5 & 2395 & 1728 & 5.6 & 635 \\
D6 & 4254 & 2328 & 7.3 & 836 \\
D7 & 2499 & 1190 & 8.4 & 960 \\
D8 & 782 & 584 & 5.4 & 613 \\
D9 & 3625 & 1938 & 7.5 & 855 \\
\hline \hline
\end{tabular}

in the models. Initially, this calibration check is held for all measured source-receiver configurations with single slope decay formation. For other configurations, with multi-slope decay formation, multiple decay times $\left(T_{1}, T_{2}\right.$.) are compared for measured versus simulated data. Just noticeable differences (JND) are utilized to assess and regulate the tuning. The sound absorption coefficient data for standard materials such as marble on concrete, stone cladding, and large-pane or multi-layer glass surfaces are well defined in various sources. These are more or less identical and mostly reflective. The critical issue is the assignment of coefficients to comparatively absorptive materials. The sound absorption performances of plaster surfaces vary considerably, especially where historical plasters are concerned (Sü Gül, 2019). For this reason, the tuning process is mostly directed towards adjusting the sound absorption coefficients of plaster surfaces. In the museum scenario and the church scenario, the materials and the architectural features vary only minimally in terms of their effect on the overall acoustical character of the building. This has also been established previously by another research group (Weitze et al., 2002). The main variation occurs when the structure is adapted for use as a mosque and the floors are covered with carpets. The carpeting is simulated by applying the absorption coefficients found for another mosque dating back to the period when Hagia Sophia served as a mosque (CAHRISMA Project, 2001). These coefficients are 0.38 for $1 \mathrm{kHz}$ and 0.12 for $250 \mathrm{~Hz}$. The scattering coefficients for different surfaces required for Ray-t are based on the quantity of surface irregularities on either small or large scale.

In the diffusion model, the marble floor of Hagia Sophia has an absorption coefficient of 0.01 for medium and low frequencies while the upper structure, which is cladded with stone facings, plaster, and mosaics, has an average sound absorption coefficient of 0.094 for $1 \mathrm{kHz}$ and 0.075 for $250 \mathrm{~Hz}$. It should be noted that the solid (for DEM) and the 3D-face models (for Ray-t) of Hagia Sophia are kept as it is utilized in the previous study (Sü Gül et al., 2019). The absorption coefficients are re-tuned for DEM and Ray-t, by checking all tested source positions. For this study, there is no significant change over DEM model. However, for Ray- $t$ the sound absorption coefficient, especially for $1 \mathrm{kHz}$, are revised for the results to be more compatible with the fieldtested data, whereas previously the same coefficients were applied for both DEM and Ray-t, as the analysis of ray tracing was not further developed or discussed in that study (Sü Gül et al., 2019). Accordingly, the sound absorption coefficients for the upper structure need to be adjusted for Ray- $t$ in order to match the field test results. In this case, the mid-frequency average sound absorption coefficient is found to be 0.082 for $1 \mathrm{kHz}$ and 0.079 for $250 \mathrm{~Hz}$. As can be seen in Table II, the JND between the simulated decay rates and the field-test results for $1 \mathrm{kHz}$ and $250 \mathrm{~Hz}$ are well below $5 \%$ and less than 1 JND (ISO, 2009).

\section{RESULTS AND DISCUSSION}

\section{A. Comparison of simulations with in situ test results}

The systematic investigation of multi-rate decay inside the interior volume of Hagia Sophia starts by comparing the results obtained during the field tests, for those sample source-receiver positions, to the energy flow decays obtained from DEM and to the sound energy decays obtained by Ray-t. Bayesian analysis is applied to impulse responses gathered from Ray-t simulations for decay parameter estimations. Table III lists the decay parameters including decay times $\left(T_{1}\right.$ and $\left.T_{2}\right)$, decay levels $\left(A_{1}\right.$ and $\left.A_{2}\right)$, and coupling quantifiersi.e., the decay ratio (DR) and the level difference $(\Delta L)$. It has previously been demonstrated that the energy flow direction reversal, expressed as a dip in the energy flow decay, is associated with the turning point in Schroeder decay functions (Xiang et al., 2009). A "dip" is generally followed by a "peak" and both the dip and the turning point indicate the time at which the second energy decay starts to dominate the first energy decay. Accordingly, the turning point times of the sound energy decays of RIRs obtained during the field tests and in the Ray-t model are compared with the energy dip times from the DEM estimates to assess their correlation.

As shown in Table III, the $T_{1}$ values from the Ray-t data are approximately $10 \%-20 \%$ higher or lower than those obtained from the field tests in cases where the sourcereceiver distance is greater than $7 \mathrm{~m}$. The differences between the $T_{2}$ values are much lower than those for the $T_{1}$

TABLE II. Comparison of decay rates (s) for source $(\mathrm{S})$ and receiver $(\mathrm{P})$ positions exhibiting single-slope characteristics obtained from field tests, Ray-t, and DEM for $1 \mathrm{kHz}$ and $250 \mathrm{~Hz}$.

\begin{tabular}{lccc}
\hline \hline & \multicolumn{3}{c}{ Decay rate $(\mathrm{s})$} \\
\cline { 2 - 4 } S\#P\# (frequency) & Field & Ray-t & DEM \\
\hline S1 P171 $(1 \mathrm{kHz})$ & 7.90 & 7.90 & 8.01 \\
S1 P8 $(1 \mathrm{kHz})$ & 8.25 & 8.00 & 8.06 \\
S2 P171 $(1 \mathrm{kHz})$ & 8.10 & 8.20 & 7.97 \\
S2 P8 $(1 \mathrm{kHz})$ & 7.93 & 8.15 & 8.01 \\
S1 P171 $(250 \mathrm{~Hz})$ & 9.60 & 9.90 & 9.80 \\
S1 P8 $(250 \mathrm{~Hz})$ & 9.80 & 10.0 & 9.88 \\
S1 P160 $(250 \mathrm{~Hz})$ & 9.78 & 10.0 & 9.82 \\
S2 P171 $(250 \mathrm{~Hz})$ & 9.80 & 10.2 & 9.80 \\
S2 P8 $(250 \mathrm{~Hz})$ & 9.71 & 10.0 & 9.86 \\
\hline \hline
\end{tabular}


TABLE III. Comparison of multi-slope sound energy decay parameters obtained from Bayesian analysis $\left(T_{1}, 1 \mathrm{st}\right.$ decay time; $T_{2}, 2$ nd decay time; $A_{1}, 1 \mathrm{st}$ decay level; $A_{2}$, 2nd decay level; DR, decay ratio; $\Delta L$, level difference) for field tests and Ray-t simulations; and comparison of turning point times (TP $\left.\mathrm{P}_{\text {time }}\right)$

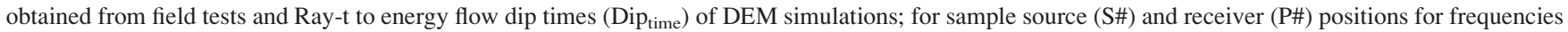
of $1 \mathrm{kHz}$ and $250 \mathrm{~Hz}$.

\begin{tabular}{|c|c|c|c|c|c|c|c|}
\hline Parameter & S1-P172 (1 kHz) & $\mathrm{S} 1-\mathrm{P} 142(1 \mathrm{kHz})$ & $\mathrm{S} 1-\mathrm{P} 160(1 \mathrm{kHz})$ & S2-P172 (1 kHz) & $\mathrm{S} 2-\mathrm{P} 160(1 \mathrm{kHz})$ & $\mathrm{S} 1-\mathrm{P} 142(250 \mathrm{~Hz})$ & $\mathrm{S} 2-\mathrm{P} 172(250 \mathrm{~Hz})$ \\
\hline Field $T_{1}(\mathrm{~s})$ & 6.61 & 6.75 & 6.69 & 6.9 & 4.89 & 8.2 & 8.54 \\
\hline Field $T_{2}(\mathrm{~s})$ & 8.89 & 9.40 & 9.47 & 9.4 & 9.7 & 10.9 & 11.3 \\
\hline Field $A_{1}(\mathrm{~dB})$ & 7.0 & 7.0 & 7.0 & 2.7 & 6.5 & 4.6 & 2.6 \\
\hline Field $A_{2}(\mathrm{~dB})$ & 9.8 & 9.7 & 9.8 & 6.1 & 12.0 & 7.8 & 6.5 \\
\hline Ray-t $T_{1}(\mathrm{~s})$ & 5.00 & 5.30 & 5.90 & 6.1 & 3.2 & 8.2 & 9.20 \\
\hline Ray-t $T_{2}(\mathrm{~s})$ & 8.90 & 8.80 & 9.1 & 9.35 & 8.3 & 10.9 & 10.9 \\
\hline Ray-t $A_{1}(\mathrm{~dB})$ & 10.0 & 4.7 & 3 & 2.1 & 2.5 & 3 & 3.0 \\
\hline Ray-t $A_{2}(\mathrm{~dB})$ & 12.8 & 6.0 & 5.3 & 5 & 7.8 & 5 & 5.0 \\
\hline Field DR & 1.3 & 1.4 & 1.4 & 1.4 & 2.0 & 1.3 & 1.3 \\
\hline Field $\Delta \mathrm{L}(\mathrm{dB})$ & 2.8 & 2.7 & 2.8 & 3.4 & 5.5 & 3.2 & 3.9 \\
\hline Ray-t DR & 1.8 & 1.7 & 1.5 & 1.5 & 2.6 & 1.3 & 1.2 \\
\hline Ray-t $\Delta \mathrm{L}(\mathrm{dB})$ & 2.8 & 1.3 & 2.3 & 2.9 & 5.3 & 2.0 & 2.0 \\
\hline Field $\mathrm{TP}_{\text {time }}(\mathrm{ms})$ & 1140 & 1048 & 1085 & 1473 & 920 & 1770 & 2285 \\
\hline Ray-t $\mathrm{TP}_{\text {time }}(\mathrm{ms})$ & 530 & 310 & 659 & 857 & 530 & 1095 & 1609 \\
\hline DEM Dip $_{\text {time }}(\mathrm{ms})$ & $480-500$ & $260-330$ & $430-560$ & 730 & $440-510$ & 340 & 870 \\
\hline
\end{tabular}

values; at most, the difference is between $5 \%$ and $10 \%$, and for certain configurations and tested octave bands-such as S1-P172 $(1 \mathrm{kHz})$ and S1-P142 $(250 \mathrm{~Hz})$ - the values are identical. This may be because the $T_{2}$ values are more representative of the decay rate of the larger volume, so that the use of single-slope cases in tuning the models to the field test results may have had a positive impact on the $T_{2}$ values. On the other hand, a recent study of some sample coupledspace scale model test configurations indicates that the JND is $10 \%$ for the first decay time and $20 \%$ for the second decay time (Luizard et al., 2015). In this previous study, the volumes are much smaller and the reverberation times of individual rooms are much lower than in the case of Hagia Sophia. So, given that the single-slope decay rates reach up to $10 \mathrm{~s}$ in Hagia Sophia for low to medium frequencies, the JNDs may still be subject to change and a value of $20 \%$ might be plausible for both $T_{1}$ and $T_{2}$ in the comparison of the different simulation techniques.

The $\Delta L$ quantifies how much lower the sound becomes during the second decaying process or $T_{2}$ relative to the first decay time $T_{1}$. The two decay times, the DR $\left(T_{2} / T_{1}\right)$, and $\Delta L$ are sufficient to quantify the double-slope characteristics of sound energy decays (Xiang et al., 2009). The $\Delta L$ results obtained from the field tests and the Ray-t model are not comparable in value, but the trend among the different sourcereceiver configurations is similar. According to both methods, for instance, the highest decay level is observed in the case of $\mathrm{S} 2-\mathrm{P} 160(1 \mathrm{kHz})$ and the lowest decay level in the case of S1P142 $(1 \mathrm{kHz})$. Last, the turning point times obtained from the field tests and the Ray-t model are compared to the energy flow dip times from the DEM estimates. The turning point times derived from the field tests are from 400 to $740 \mathrm{~ms}$ longer than those obtained from the Ray-t model, depending on the receiver position. It should be noted that the closest position tested in the field experiments is $7 \mathrm{~m}$ away from the sound source (S1$\mathrm{P} 172$ ), whereas the most distant receiver locations (S1-P160 and S2-P172) in cases where a double-slope pattern is observed are almost $30 \mathrm{~m}$ away from the sound source. Consequently, differences in source-receiver distances explain some of the variations in the turning point times obtained through the use of different methods. On the other hand, the Ray- $\mathrm{TP}_{\text {times }}$ are 0 to $100 \mathrm{~ms}$ longer than the DEM flow dip times for $1 \mathrm{kHz}$ and approximately $750 \mathrm{~ms}$ longer for $250 \mathrm{~Hz}$. It can be stated that the turning point times derived from the field test data are consistently longer than those obtained from both the Ray-t and DEM models. This is attributable to the fact that the DEM solution does not take into account the early decay component but is only valid at least two or three mean free times after the direct sound (Xiang et al., 2013). The differences between the multi-slope sound energy decay parameters of tested scale models and numerical simulations have also been noted in a previous study, where the variances are even greater for different numerical methods (Weber and Katz, 2019).

It will be useful to discuss and visualize a specific example of sound energy decay and of the comparisons of the sound energy flow decay as obtained from the different methods. For this purpose, S2-P172 has been selected as a sample configuration. Figure 2 (left) presents the Bayesian decay analysis of the data obtained from the field tests for frequencies of $1 \mathrm{kHz}$ (top) and $250 \mathrm{~Hz}$ (bottom). The two sloping straight lines indicate the decay slopes of the individual exponential decay terms and the third component relates to the background noise, which is not present for either in the Ray-t model, (Fig. 2, center) or in the DEM simulations (Fig. 2, right). As long as the noise term is sufficiently low from the signal, the impulse response can reliably be analyzed for multi-slope formation. In Fig. 2 (right), sound energy flow dips are easily identifiable for frequencies of both $1 \mathrm{kHz}$ (top) and $250 \mathrm{~Hz}$ (bottom), indicating the energy flow return that arises due to the exchange of sound energy between different interconnected domains or locations within Hagia Sophia's interior volume. The energy 

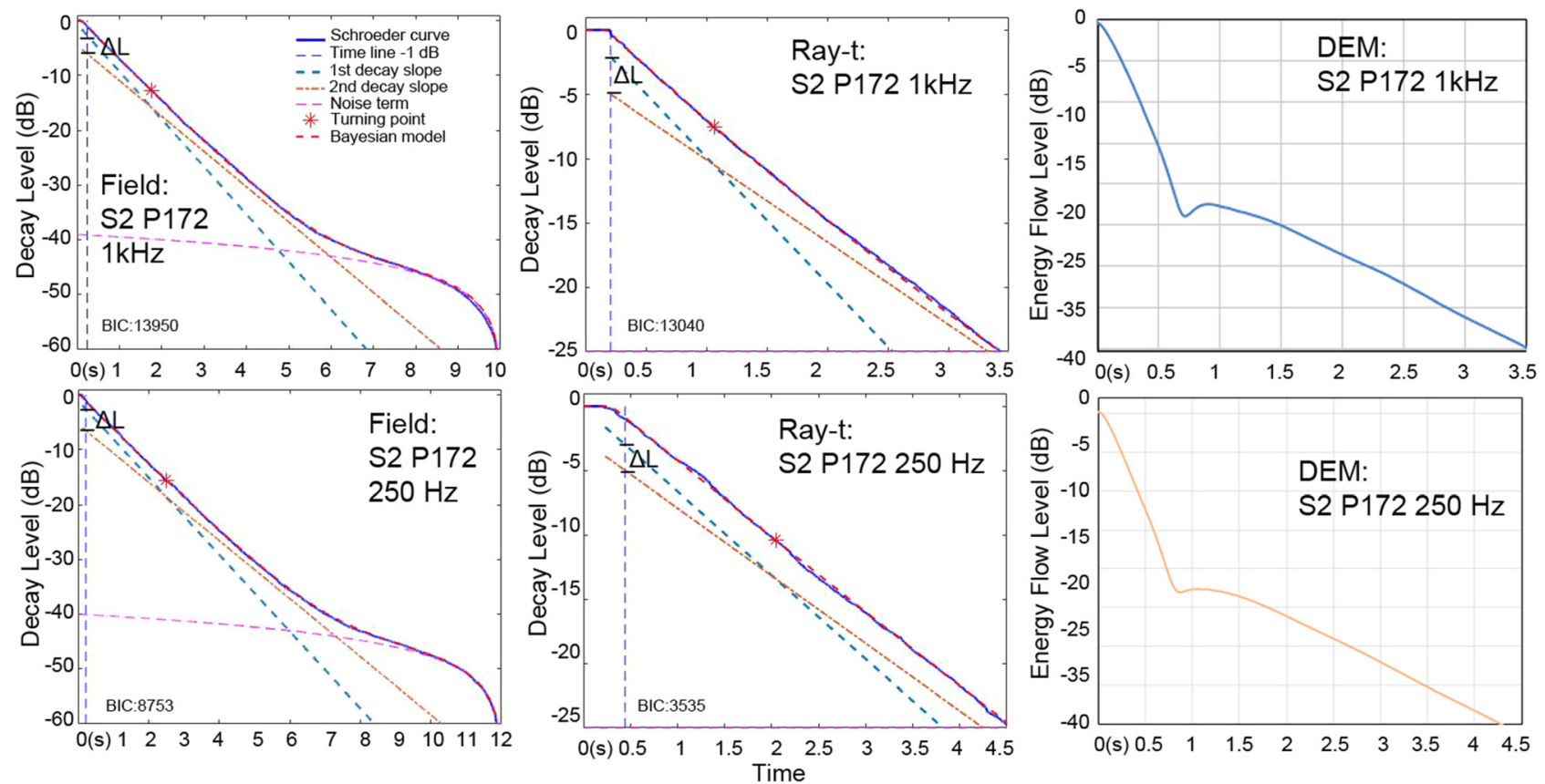

FIG. 2. (Color online) Sound energy decay for domain D0-a2 and source-receiver configuration S2-P172 at frequencies of $1 \mathrm{kHz}$ (above) and 250 Hz (below) based on data obtained from in situ tests (full decay, left), Ray-t (close-up view, center), and sound energy flow decay obtained by DEM (close-up view, right).

flow returns can also be observed through the reversal of energy flow vectors in a time-dependent DEM solution. Figure 3 shows a sample flow vector return pattern for source-receiver configuration S2-P172 and $250 \mathrm{~Hz}$. The energy flow vectors at the receiver P172 (indicated with a blue dot) can be followed in time instants before $(450 \mathrm{~ms})$ and after $(1300 \mathrm{~ms})$, for which the energy flow dip time is $870 \mathrm{~ms}$ (see Fig. 2 bottom-right). The depth of the dip is indicative of the strength of the coupling. The following sections will discuss these matters with reference to the entire interior volume of the building.

\section{B. Energy flow decay investigations and Bayesian analysis results for museum state}

This study analyzes the sound energy flow decays obtained from DEM simulations using two different source positions and 980 receiver positions distributed throughout the entire interior volume of Hagia Sophia. The complete analysis is initially performed for $1 \mathrm{kHz}$; later, for $250 \mathrm{~Hz}$. These analyses are conducted for the state of the building in which the field tests were conducted; i.e., when it was in use as a museum with a marble floor. Afterwards, some sample positions are also tested for the state of the building with a carpeted floor, representing the mosque case, which is also the most recent state of the building. The domains to which individual diffusion coefficients are attributed, the subdomains, and the receiver positions at varying elevations are coded in Fig. 1 and the Appendix. In order to discuss some typical sound energy flow dip patterns, and to explain the findings briefly, a number of sub-domains and receiver positions within those sub-domains are selected for further discussion. Figure 4 presents the sound energy flow decays
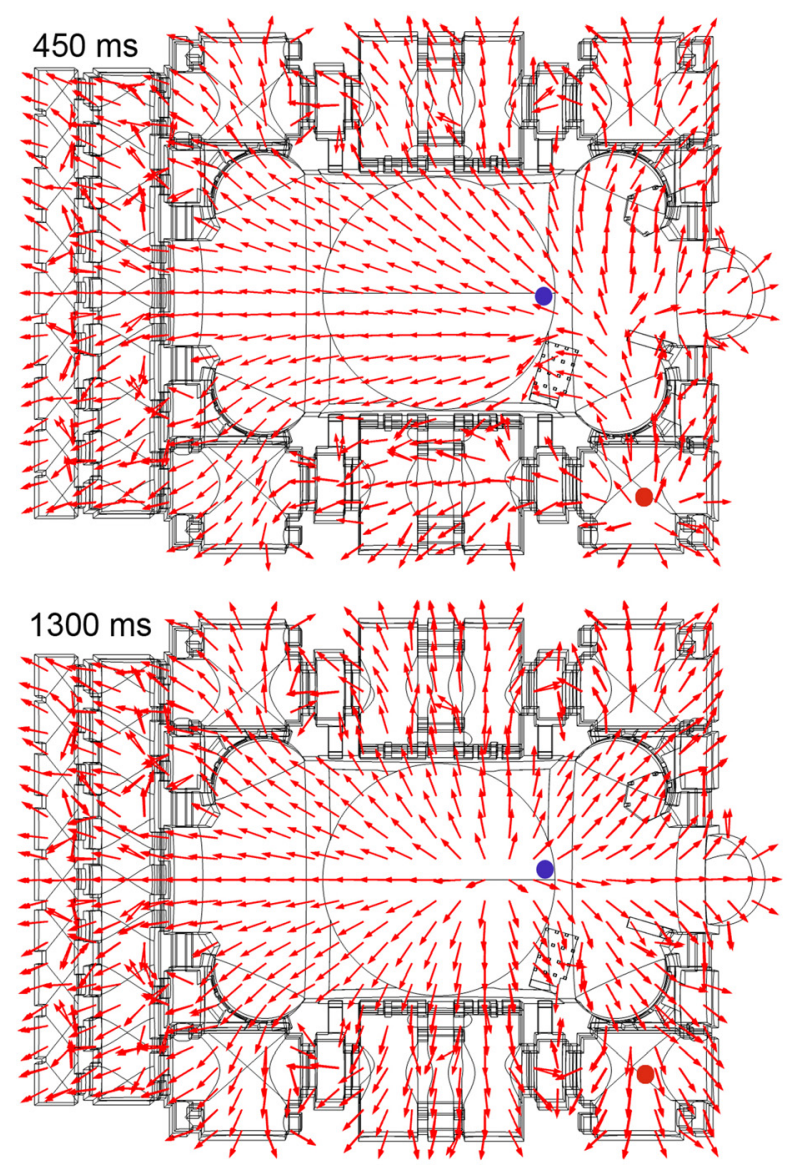

FIG. 3. (Color online) Energy-flow vector maps (plan views) of DEM solution at $250 \mathrm{~Hz}$, for S2 (red dot), P172 (blue dot), for times of $450 \mathrm{~ms}$ (above) and $1300 \mathrm{~ms}$ (below). 
obtained for source \#1 (S1) and Fig. 5 shows the representative results for source \#2 (S2).

The source (S1), as in the in situ tests, is located inside the main prayer zone, on the central axis, $20 \mathrm{~m}$ away from the apse wall. The source is in front of the mihrab, and as close to it as was practically possible at the time when the field tests were performed, due to the ongoing restoration works and restricted/closed zones. The closest simulated receiver position on the horizontal (plan) axis is $5.7 \mathrm{~m}$ away from $\mathrm{S} 1$ and the farthest is almost $70 \mathrm{~m}$ away. The simulated receiver positions are at different elevations, ranging from $1.20 \mathrm{~m}$, a typical measured receiver height, up to $52.4 \mathrm{~m}$, which is the highest elevation inside the structure-just $1.54 \mathrm{~m}$ below the central vertical axis of the main dome (see Figs. 1 and 6). D0 is the main volume underneath the central dome (the main prayer hall or naos) and the two semidomes. D0-a is the volume underneath the central dome, DO-b is the volume underneath the semi-dome closer to the narthex, and D0-c is the volume underneath the second semi-dome, which is closer to the apse wall as well as to S1.

According to the analysis, for sub-domain DO-b, the energy flow decays indicate a single-slope pattern for all receiver positions. The smooth energy flow decay pattern shows no indication of a dip and is very similar to the result for D4-7 S1 given in Fig. 4. The minimum distance from source to receiver for the receiver positions in domain D0-b is $33 \mathrm{~m}$. In this case, both the source and the receiver are within the largest volume in the building, and separated by the arches, almost $30 \mathrm{~m}$ in width, that couple the subvolume under the semi-dome to the main volume underneath the central dome (i.e., the naos). Energy flow decays with a noticeable sound energy flow dip start to occur in D0$\mathrm{a}$, which is the main volume underneath the central dome and the largest of all the sub-domains. In D0-a, flow dips are observed for simulated positions at horizontal (plan) distances of between 5.7 and $13 \mathrm{~m}$ from S1 and at vertical (elevation) distances of $1.7 \mathrm{~m}$ to $40 \mathrm{~m}$ from S1 (Fig. 6). Examples of the energy flow dips in this sub-domain are presented in Fig. 4 (D0-a2 S1). The energy flow dips disappear $16 \mathrm{~m}$ away from the source on the horizontal plane, in the direction of the narthex, and at all elevations above $45 \mathrm{~m}$. The energy flow decays directly underneath the central dome show no energy flow dip at any of the receiver positions at any elevation. The sound energy decay flows tend to show a more convex pattern as the elevation increases (above $42 \mathrm{~m}$ above ground), but none of those positions generate a
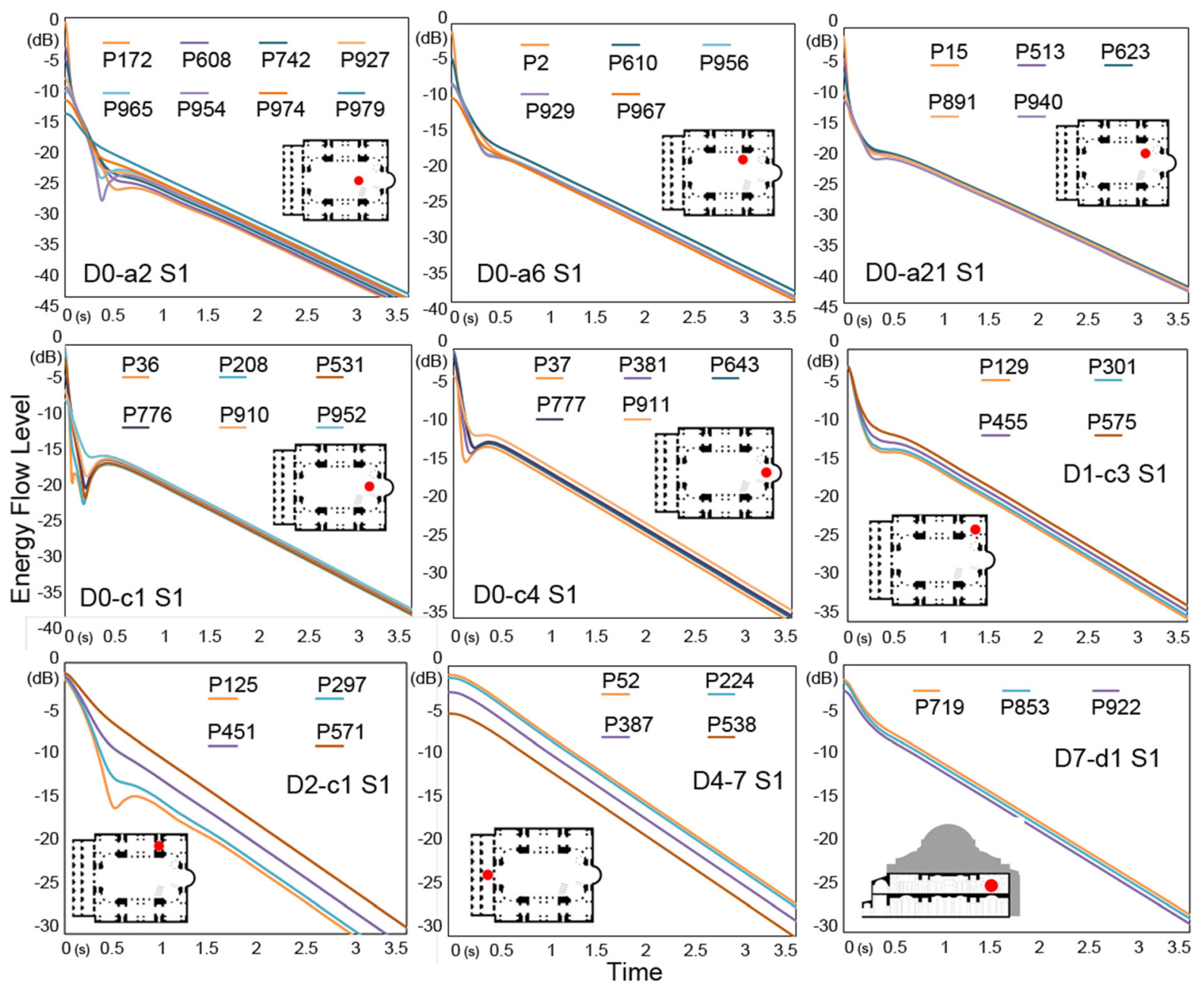

FIG. 4. (Color online) Sample sound energy flow decays obtained from DEM simulations for different domains and different receiver heights within each domain for sound source $\mathrm{S} 1$ and for $1 \mathrm{kHz}$; marble floor (museum state). 

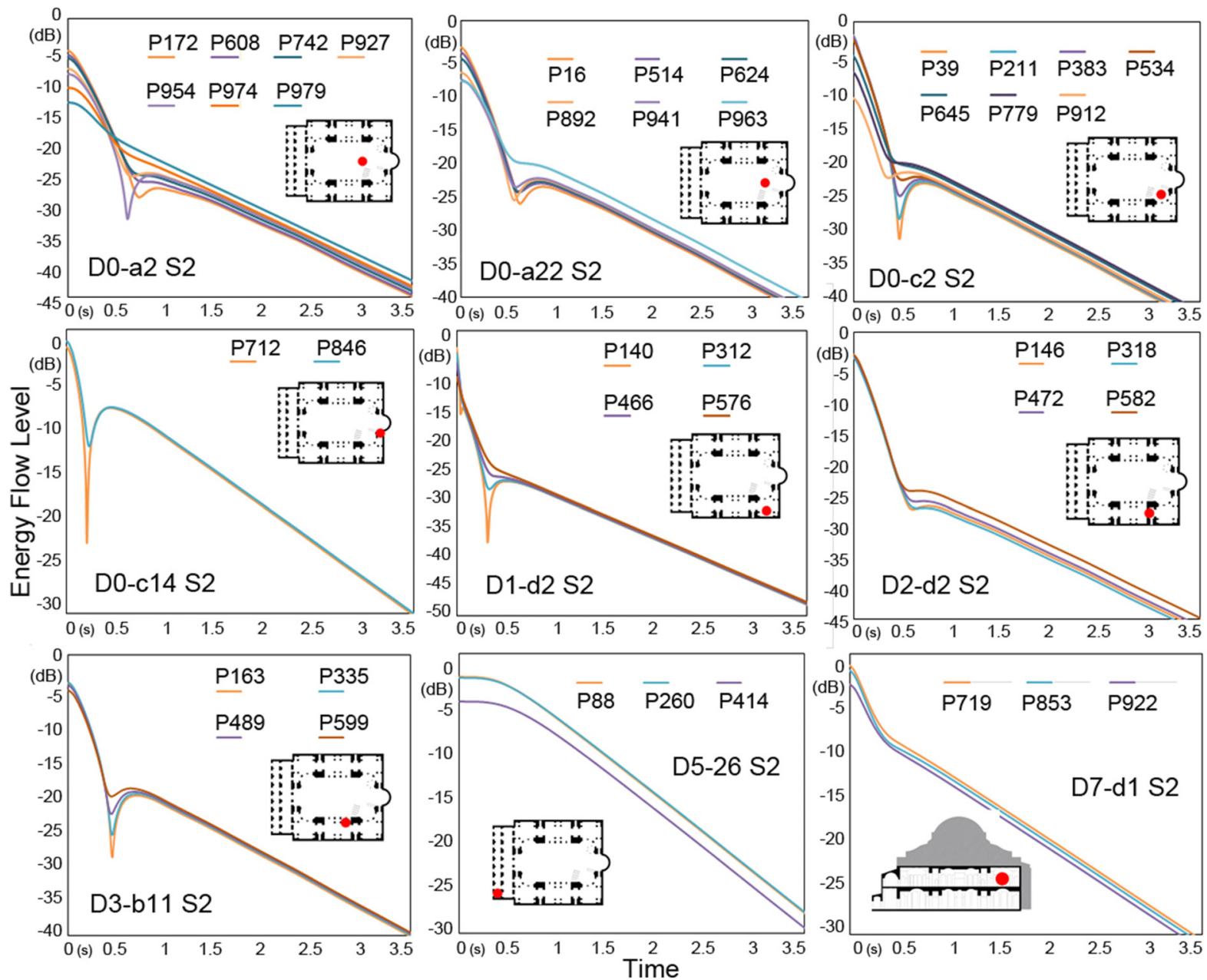

FIG. 5. (Color online) Sample sound energy flow decays obtained from DEM simulations for different domains and different receiver heights within each domain for sound source $\mathrm{S} 2$ and for $1 \mathrm{kHz}$; marble floor (museum state).

double- or multi-slope decay pattern neither in the Ray-t simulations.

$\mathrm{D} 0$-a2 is the sub-domain underneath the main dome representing the closest receiver position to $\mathrm{S} 1$. There is a clear energy flow dip and the double-slope energy decay is also corroborated by the in situ test data (Table III) for the receiver position $1.20 \mathrm{~m}$ above ground (S1-P172). At this position as the elevation from the ground as well as the distance from the source increases, the depth of the energy flow dip also tends to increase, reaching its maximum level at $30 \mathrm{~m}$ above ground (S1-P954) and then tending to dissolve slowly before disappearing altogether. In the subdomain D0-a6 (see Figs. 1 and 4), the dip reaches its maximum depth at an elevation of $36 \mathrm{~m}$; otherwise, the pattern is similar at the various elevations, indicating a relatively weak-to-medium case of flow dip occurrence. D0-a7 is the sub-domain that mirrors D0-a6, taking S1 as the mirror axis. As expected, the results are largely identical to those for DO-a6, further supporting the findings. D0-a14 and D0-a20, which are the receiver positions within DO-a that are closest to the corners of one of the main piers towards the apse, are the farthest receiver zones within D0 that demonstrate energy flow dips for the sound source S1.
For D0-a20, which is $14 \mathrm{~m}$ away from $\mathrm{S} 1$ on the horizontal plane, the results for the different elevations are mostly similar in pattern, showing a shallow dip. D0-a23 includes the group of receivers right behind the mahfil of the muezzin (see Figs. 1 and 6). In terms of source-receiver distance, this domain mirrors D0-a20 (with reference to S1), so the pattern of energy flow dips is similar. D0-a21 is the receiver zone group right underneath the main arch, carrying the central dome, that is closest to the apse wall. The nearest receiver position in this group to $\mathrm{S} 1$ is $\mathrm{P} 15$, which is $7 \mathrm{~m}$ away. Here, the dips tend to increase with the elevation, reaching their greatest depth at the highest elevation, the receiver position P940, which is $30 \mathrm{~m}$ above the ground.

The domain D0-c accommodates the receiver points underneath the first semi-dome on the side of the apse wall and above the minbar and mihrab. S1 is located closer to this semi-dome than to DO-b. This domain contains the greatest number of receiver positions, at different elevations, for which flow dips are observed. D0-c1, which is the zone underneath the central axis of the semi-dome (Fig. 4), may be given as an example and as a particularly strong case. The receiver position in DO-c1, which has the lowest elevation (P36), is $8.6 \mathrm{~m}$ away from $\mathrm{S} 1$ on the horizontal plane. 

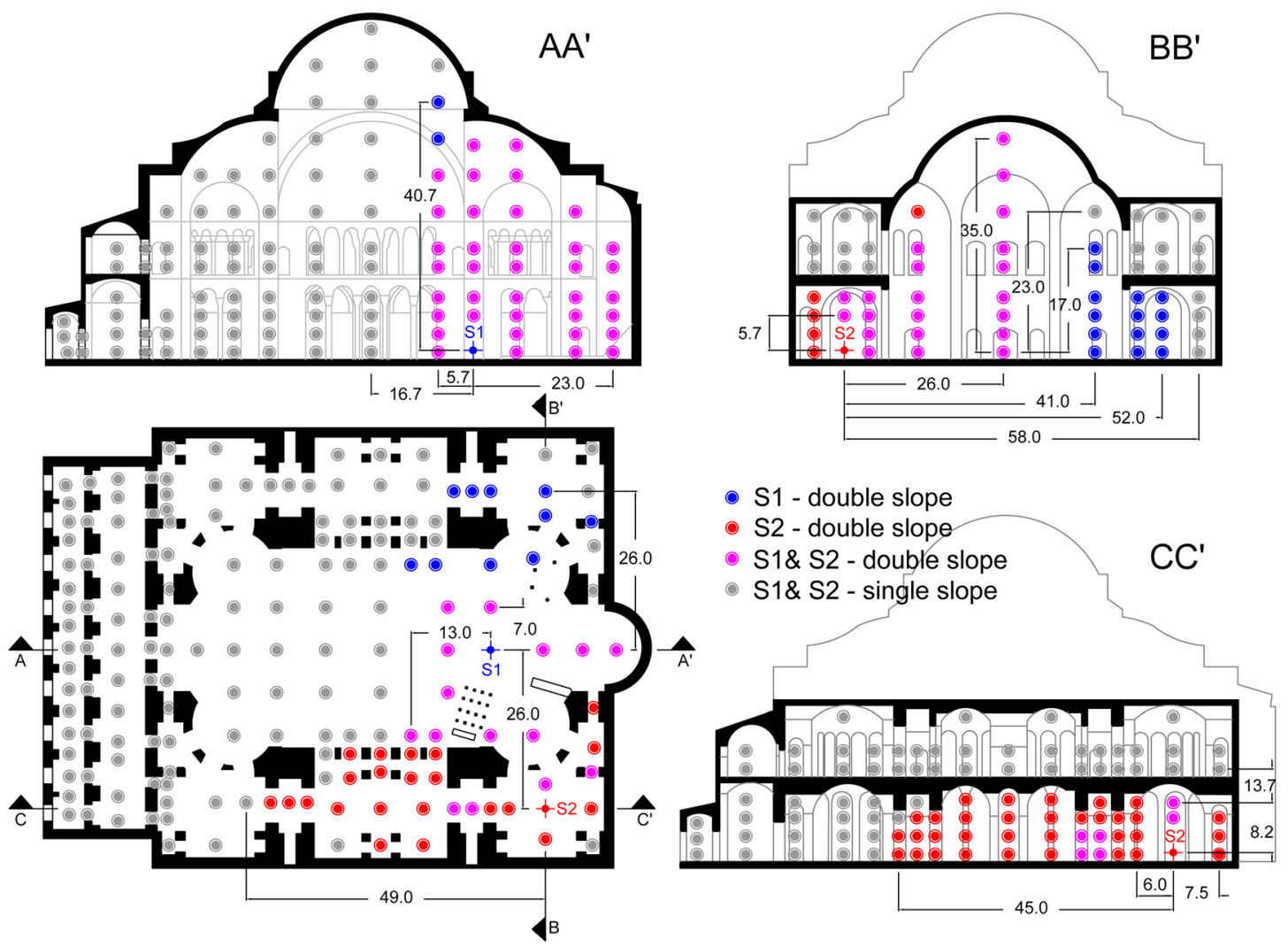

FIG. 6. (Color online) Plan and section views of the overall distribution of the receiver positions highlighting energy flow dips supported by double-slope energy decay patterns obtained from Ray-t simulations analyzed within the Bayesian framework; double-slope zones for S1 (blue), double-slope zones for S2 (red), double-slope zones for both S1 and S2 (magenta), and single-slope zones for both S1 and S2 (gray); dimensions are in meters.

Two energy flow dips are observed for that specific position, one occurring at $80 \mathrm{~ms}$ and the other at $190 \mathrm{~ms}$. This is similar to the double-dip pattern observed for D1-d2 S2 (Fig. 5). At the remaining elevations, single distinctive sound energy flow dips are observed for the source S1 (Fig. 3, DO-c1 S1). The receiver group D0-c4 generates strong energy flow dips at different elevations. The lowest receiver position in this group, P37, is $15 \mathrm{~m}$ away from $\mathrm{S} 1$ towards the side of the apse.

Other locations where energy flow dips are observed for the sound source S1 are D1-c, D1-d, D2-c, and D2-d (see Figs. 1 and 4). The case of D1 may be illustrated with the case of the receiver position group D1-c3, which is right on the border of the arch connecting from D1-c to D0-c. This group of receiver positions generates energy flow dips with a wider base. The same situation is observed for the subdomain which it mirrors. Underneath the corner fan-vault, the dips are observed for only $5 \mathrm{~m}$ into the space after the separating arch, after which they disappear. For the barrelvaulted D2-c sub-domains, connecting D1-c sub-domains to D3-a sub-domains, the dip is very marked at the lowest elevation (as for P125) and weakens as the elevation increases from $1.2 \mathrm{~m}$ to $10.2 \mathrm{~m}$ above ground (Fig. 4, D2-c1 S1). None of the other domains and sub-domains (see Fig. 1), comprising D1a-b, D2a-b, D3a-b, D4, and D5 on the ground floor and D7a-b-c-d, D8a-b-c-d, D9a-b, and D6 at the balcony level, indicate a potential flow dip, and there is, therefore, no indication of multi-slope energy decay. For example, D4-7 constitutes a perfect single-slope case with a linear energy-flow decay. D7-d1 is the case that shows the most convex pattern of energy flow decay among all the balcony level results, but this is still not strong enough to indicate a flow dip or a potential multi-slope. These cases are also checked through Ray-t and later Bayesian analysis, the results of which support the finding that a single-slope energy decay pattern prevails in such positions and in the domains farther away from the sound source S1.

Figure 5 presents the energy flow decay patterns obtained for selected receiver positions for the source position S2, which is in the side aisle, underneath the corner fanvault. From the coupled-space point of view, source S2 is located within a comparatively smaller volume and hence a volume with a lower natural reverberation time in decoupled condition. The position is also asymmetric with regard to the plan of the building. All 980 receiver positions are analyzed again, and those generating dips of various levels are presented in Fig. 5. Accordingly, D0-a, D0-c, D1-d, D2-d, and D3-b are the sub-domains where energy flow dips are most strongly observed (see Figs. 5 and 6). D0-a2 shows clear dips for $\mathrm{S} 2$, especially up to a height of $42 \mathrm{~m}$ above ground, with the most prominent for P954 at $30.2 \mathrm{~m}$ above ground. D0-a7 and Do-a22 also generate noticeable dips. These receiver groups are all close to the border between the D0-a and D0-c sub-domains, and the maximum distance of the receiver positions from $\mathrm{S} 2$ on the horizontal plane is $36 \mathrm{~m}$. All the receiver points in D0-c, which are located below the central axis of the structure (see Fig. 1) or towards 
the side of the aisle accommodating S2 (or sub-domain D1-d), generate energy flow dips in DEM and double-slope pattern indicated by Ray-t simulations. D0-c2 and D0-c14 are presented as sample receiver groups in Fig. 5. The closer one approaches the border, or the arch connecting D0-c to D1-d, the deeper the dips become. The strongest flow dips are observed in the receiver groups that are closest to the source in D1-d. The shortest distance from the source horizontally is $4 \mathrm{~m}$ and the shortest distance vertically is $5.7 \mathrm{~m}$ above the source. The sub-domains D2-d and D3-b, exemplified in Fig. 4 by D3-b15 and D3-b11, also yield energy flow dips, and this finding is supported by double-slope energy decay outputs from the Bayesian analysis of the Ray-t simulations for the same positions. As a specific note, the receiver position P163 within D3-b11 shows one of the sharpest energy flow dips for $\mathrm{S} 2$. This receiver position has no direct sight-line to the sound source, thus is located in the shadow-zone, but still is within the critical distance from the source where energy flow dips are observed (Fig. 6). Overall, energy flow dips occur for $\mathrm{S} 2$ in a zone within $45 \mathrm{~m}$ of the source including the subdomains D1-d, D2-d, D3-b, and D2-b on the side aisle in which the source is located. The energy flow decays at the receiver positions located in all other areas, whether on the ground floor or at balcony level, are observed to be smooth and without dips. Once again, this finding is supported by the Bayesian analysis of the data obtained by the Ray- $t$ method, all of which demonstrate single-slope sound energy decay. Figure 6 presents an overview (on plan and section views) of the receiver positions that display single- and double-slope patterns or marked energy flow dips when either S1 or S2 is activated. The Appendix is also utilized to indicate single versus double-decay occurrence. Some instructive source-receiver dimensions are highlighted (Fig. 6). This condensed mapping relies on both the DEM energy flow decay results and on the sound energy decay analysis of impulses obtained from Ray-t simulations analyzed by Bayesian analysis.

Apart from energy flow decay and flow dip investigations, overall receiver positions are examined through the Bayesian analysis for both S1 and S2 source locations for $1 \mathrm{kHz}$. The results out of impulse responses gathered by Ray-t simulations are presented in Table IV. The table includes number of positions in each sub-domain, mean value and standard deviation $(\sigma)$ of T30 values for single slope cases, mean value and $\sigma$ of decay rates $\left(T_{1}, T_{2}\right)$, and $\Delta L$ results for multi-slope cases. Accordingly, the double slope decay occurs at $17 \%$ of overall receiver positions for $\mathrm{S} 1$, and $19 \%$ of overall receiver positions for $\mathrm{S} 2.7 .97 \mathrm{~s}$ is the average $T 30$ value for both $\mathrm{S} 1$ and $\mathrm{S} 2$, whereas $\sigma$ is $0.08 \mathrm{~s}$ for $\mathrm{S} 1$ and $0.28 \mathrm{~s}$ for $\mathrm{S} 2$. This indicates that the single slope energy decay rate within the volume is more dispersed for S2 than S1, which is expectable for this off-axis source position. Other than that, the $T 30$ values are quite evenly distributed. Double slope case results are as follows; mean value for $T_{1}$ is $5.59 \mathrm{~s}$ for $\mathrm{S} 1$ and it is $3.55 \mathrm{~s}$ for $\mathrm{S} 2$, whereas $\sigma$ is $0.20 \mathrm{~s}$ for $\mathrm{S} 1$ and $1.35 \mathrm{~s}$ for $\mathrm{S} 2$. The deviation of early
TABLE IV. Bayesian analysis overview for receivers in overall subdomains for $\mathrm{S} 1$ and $\mathrm{S} 2$, for $1 \mathrm{kHz} ; n$ (number of positions), mean and $\sigma$ values of $T 30, T_{1}, T_{2}$, and $\Delta L$.

\begin{tabular}{|c|c|c|c|c|c|c|c|c|c|c|}
\hline \multirow{2}{*}{$\begin{array}{l}\text { S1 } \\
\text { Domain }\end{array}$} & \multirow{2}{*}{$\begin{array}{c}n \\
\text { single }\end{array}$} & \multicolumn{2}{|c|}{ T30 } & \multirow{2}{*}{$\begin{array}{c}n \\
\text { double }\end{array}$} & \multicolumn{2}{|c|}{$T_{1}$} & \multicolumn{2}{|c|}{$T_{2}$} & \multirow{2}{*}{$\begin{array}{c}\Delta \mathrm{L} \\
\text { mean }\end{array}$} & \multirow{2}{*}{$\begin{array}{c}\mathrm{dB} \\
\sigma\end{array}$} \\
\hline & & Mean & $\sigma$ & & mean & $\sigma$ & mean & $\sigma$ & & \\
\hline D0-a & 145 & 8.00 & 0.03 & 93 & 5.49 & 0.60 & 8.83 & 0.20 & 2.7 & 0.8 \\
\hline D0-b & 114 & 8.01 & 0.03 & 0 & - & - & - & - & - & - \\
\hline D0-c & 26 & 7.96 & 0.16 & 39 & 5.66 & 0.27 & 8.83 & 0.17 & 2.6 & 0.7 \\
\hline D1-a & 32 & 7.88 & 0.05 & 0 & - & - & - & - & - & - \\
\hline D1-b & 28 & 8.08 & 0.04 & 0 & - & - & - & - & - & - \\
\hline D1-c & 10 & 8.06 & 0.04 & 8 & 5.7 & 0.10 & 8.95 & 0.05 & 3.5 & 0.5 \\
\hline D1-d & 14 & 8.09 & 0.07 & 8 & 5.33 & 0.01 & 8.83 & 0.02 & 1.3 & 0.0 \\
\hline D2-a & 10 & 8.00 & 0.02 & 0 & - & - & - & - & - & - \\
\hline D2-b & 10 & 7.99 & 0.04 & 0 & - & - & - & - & - & - \\
\hline D2-c & 0 & - & - & 12 & 5.26 & 0.05 & 8.88 & 0.04 & 1.5 & 0.3 \\
\hline D2-d & 4 & 7.91 & 0.04 & 8 & 6.12 & 0.09 & 8.92 & 0.09 & 1.6 & 0.1 \\
\hline D3-a & 64 & 7.94 & 0.03 & 0 & - & - & - & - & - & - \\
\hline D3-b & 64 & 7.95 & 0.07 & 0 & - & - & - & - & - & - \\
\hline D4 & 52 & 7.93 & 0.02 & 0 & - & - & - & - & - & - \\
\hline D5 & 69 & 7.90 & 0.04 & 0 & - & - & - & - & - & - \\
\hline D6 & 26 & 8.02 & 0.07 & 0 & - & - & - & - & - & - \\
\hline D7-a & 20 & 8.05 & 0.02 & 0 & - & - & - & - & - & - \\
\hline D7-b & 19 & 8.07 & 0.03 & 0 & - & - & - & - & - & - \\
\hline D7-c & 11 & 7.86 & 0.01 & 0 & - & - & - & - & - & - \\
\hline D7-d & 13 & 7.78 & 0.02 & 0 & - & - & - & - & - & - \\
\hline D8-a & 6 & 7.91 & 0.04 & 0 & - & - & - & - & - & - \\
\hline D8-b & 6 & 8.14 & 0.01 & 0 & - & - & - & - & - & - \\
\hline D8-c & 6 & 7.94 & 0.05 & 0 & - & - & - & - & - & - \\
\hline D8-d & 6 & 7.94 & 0.01 & 0 & - & - & - & - & - & - \\
\hline D9-a & 24 & 7.93 & 0.05 & 0 & - & - & - & - & - & - \\
\hline D9-b & 24 & 8.03 & 0.07 & 0 & - & - & - & - & - & - \\
\hline \multicolumn{11}{|l|}{$\mathrm{S} 2$} \\
\hline D0-a & 176 & 7.95 & 0.05 & 62 & 5.42 & 1.28 & 8.63 & 0.36 & 1.7 & 0.6 \\
\hline D0-b & 114 & 7.98 & 0.07 & 0 & - & - & - & - & - & - \\
\hline D0-c & 29 & 8.02 & 0.02 & 36 & 5.24 & 1.57 & 8.84 & 0.24 & 2.6 & 2.2 \\
\hline D1-a & 32 & 8.04 & 0.05 & 0 & - & - & - & - & - & - \\
\hline D1-b & 28 & 8.07 & 0.03 & 0 & - & - & - & - & - & - \\
\hline D1-c & 18 & 8.09 & 0.02 & 0 & - & - & - & - & - & - \\
\hline D1-d & 4 & 6.62 & 0.07 & 18 & 1.97 & 0.10 & 8.14 & 0.08 & 12.9 & 0.6 \\
\hline D2-a & 10 & 7.95 & 0.03 & 0 & - & - & - & - & - & - \\
\hline D2-b & 2 & 7.91 & 0.04 & 8 & 3.15 & 0.15 & 8.48 & 0.03 & 3.7 & 0.5 \\
\hline D2-c & 12 & 7.91 & 0.03 & 0 & - & - & - & - & - & - \\
\hline D2-d & 0 & - & - & 12 & 2.18 & 0.12 & 8.16 & 0.11 & 11.5 & 0.7 \\
\hline D3-a & 64 & 7.96 & 0.03 & 0 & - & - & - & - & - & - \\
\hline D3-b & 16 & 7.86 & 0.05 & 48 & 3.33 & 0.76 & 8.39 & 0.43 & 3.7 & 1.3 \\
\hline D4 & 52 & 8.03 & 0.12 & 0 & - & - & - & - & - & - \\
\hline D5 & 69 & 8.08 & 0.15 & 0 & - & - & - & - & - & - \\
\hline D6 & 26 & 8.13 & 0.09 & 0 & - & - & - & - & - & - \\
\hline D7-a & 20 & 8.03 & 0.01 & 0 & - & - & - & - & - & - \\
\hline D7-b & 19 & 8.04 & 0.01 & 0 & - & - & - & - & - & - \\
\hline D7-c & 11 & 8.08 & 0.02 & 0 & - & - & - & - & - & - \\
\hline D7-d & 13 & 8.09 & 0.01 & 0 & - & - & - & - & - & - \\
\hline D8-a & 6 & 8.01 & 0.02 & 0 & - & - & - & - & - & - \\
\hline D8-b & 6 & 8.10 & 0.00 & 0 & - & - & - & - & - & - \\
\hline D8-c & 6 & 8.10 & 0.08 & 0 & - & - & - & - & - & - \\
\hline D8-d & 6 & 8.02 & 0.01 & 0 & - & - & - & - & - & - \\
\hline D9-a & 24 & 8.02 & 0.10 & 0 & - & - & - & - & - & - \\
\hline D9-b & 24 & 8.07 & 0.07 & 0 & - & - & - & - & - & - \\
\hline
\end{tabular}


decay rate $\left(T_{1}\right)$ values is greater for $\mathrm{S} 2$ again. This is specifically due to the receiver positions in close-by locations to $\mathrm{S} 2$, with high levels of $\Delta L$, in domains such as D1-d, D-2d versus more distant locations that still indicate double slope formation but with weak $\Delta L s$, like in the case of D0-a and D0c receivers. On the other hand, mean value for $\mathrm{T}_{2}$ is $8.87 \mathrm{~s}$ for $\mathrm{S} 1$ and it is $8.44 \mathrm{~s}$ for $\mathrm{S} 2$, whereas $\sigma$ is $0.07 \mathrm{~s}$ for $\mathrm{S} 1$ and $0.24 \mathrm{~s}$ for $\mathrm{S} 2$. Later energy decay rate $\left(T_{2}\right)$ for $\mathrm{S} 1$ and $\mathrm{S} 2$ are higher than $T 30$ values estimated for single slope cases, whereas the deviation among different positions within the volume is quite similar for single and double slope cases.

Another discussion is presented here on energy flow dip levels versus $\Delta L$, which are the indicators of how strong or weak a non-exponential energy decay is. According to Figs. 4 and 5, in overall flow dip indicating receiver positions for S1, the dip levels are smaller and shallower than those obtained for $\mathrm{S} 2$. The maximum relative dip level (from the starting point of the flow to the lowest point of the dip) is around $-15 \mathrm{~dB}$ for $\mathrm{S} 1$, while it reaches almost to $-35 \mathrm{~dB}$ for $\mathrm{S} 2$. This possible indication of the degree of coupling is also investigated by means of Ray-t and Bayesian analysis. The decay times, decay levels, and coupling quantifiers-i.e., the DR and $\Delta L$ obtained from Ray-t simulations and the relative flow dip levels shown by DEM simulations for selected configurations at $1 \mathrm{kHz}$-are summarized in Table V. The table shows that the $T_{1}$ values are affected more than the $T_{2}$ values by the location of the source and the distance of the receiver from the source. This finding also supports the conclusions of Anderson and Anderson (2000) regarding large interiors with coupled rooms.

According to Table $\mathrm{V}$, the $\Delta L$ of from 2 to $3 \mathrm{DB}$, which indicates a relatively weak double-slope case, corresponds to energy flow dips ranging from -14 to $-18 \mathrm{~dB}$, as in the cases of S1-P965, S1-P954, S1-P929, S1-P381, S2-P642, and S2-P161. For the $\Delta L$ range between 6 and $11 \mathrm{~dB}$, the flow dip levels drop to the range from -23 to $-35 \mathrm{~dB}$, as in the cases of S2-P211, S2-P137, S2-P141, and S2-P146. This second group highlights the strongest double-slope cases. These are mostly observed for the source position S2 and for the receiver positions located closest to the source within the same domain, which is much smaller in volume, in comparison to the main volume (see Table I). Likewise, DRs of 1.5-1.6 correspond to the first group, consisting of weak double slope cases, and DRs of 3.5-4 correspond to the second group of stronger double-slope cases. This does not necessarily mean, or prove, that the quantitative relationship between the flow dip levels obtained from DEM and the $\Delta L$ and DR values for other structures will be the same as those given here. However, it shows that different identifiers from different simulation methods point to a similar pattern in the degree of coupling.

In order to illustrate the different levels of flow dips, and hence the degree of coupling, further, two cases are selected from Table V, namely, S1-P954 from sub-domain D0-a2 and S2-P141 from sub-domain D1-d3. Figure 7 presents the Bayesian analysis-processed sound energy decay graphs (data from Ray-t simulation) and sound energy flow decays (data from DEM) for these two cases. The turning points, individual decay slopes, and $\Delta L s$ for these two source-receiver configurations are indicated on the sound energy decay graphs (Fig. 7, left and center) and the flow decays are plotted on the same graph (Fig. 7, right). S2P141, which is a strong case, exhibits a DR of 4.2 , a $\Delta L$ of 13.3DB, and a flow dip at around $35 \mathrm{~dB}$ below $0 \mathrm{~dB}$. S1P954, as a relatively weak case, exhibits a DR of 1.7 , a $\Delta L$ of $2.5 \mathrm{~dB}$, and a flow dip at around $18 \mathrm{~dB}$ below 0 .

This study has initially concerned with the overall acoustical performance of the entire interior volume of Hagia Sophia for $1 \mathrm{kHz}$, investigating every position on the grid. $1 \mathrm{kHz}$, as one of the mid-band frequencies, is more reliable to compare different simulation techniques. For octave bands above $1 \mathrm{kHz}$, very similar trends have been observed for the source and receiver positions used in situ tests (Sü Gül et al., 2018). The distribution of multi-slope patterns, in overall volume, at these higher frequencies might therefore not differ greatly from the results obtained from the midoctave band $1 \mathrm{kHz}$. To analyze the performance of the structure at low frequencies, $250 \mathrm{~Hz}$ is selected for analysis. In fact, the results obtained from Bayesian analysis of the in situ test findings for frequencies of 250 and $125 \mathrm{~Hz}$ are almost identical (Sü Gül et al., 2018). Given the MFPs of Hagia Sophia (see Table I) due to its immense volume, the

TABLE V. Comparison of multi-slope sound energy decay parameters from Bayesian analysis of Ray-t simulations with relative flow dip level of DEM simulations for sample source $(\mathrm{S \#})$ and receiver positions $(\mathrm{P \#})$ for $1 \mathrm{kHz}$.

\begin{tabular}{|c|c|c|c|c|c|c|c|c|}
\hline Domain & S\#P\# & $T_{1}(\mathrm{~s})$ & $T_{2}(\mathrm{~s})$ & $A_{1}(\mathrm{~dB})$ & $A_{2}(\mathrm{~dB})$ & $\operatorname{DR}\left(T_{2} / T_{1}\right)$ & $\Delta L(\mathrm{~dB})$ & Flow dip level (relative dB) \\
\hline D0-a2 & S1 P965 & 5.7 & 8.7 & 4.0 & 6.0 & 1.5 & 2.0 & -14.0 \\
\hline D0-a2 & S1 P954 & 5.4 & 9.2 & 3.5 & 6.0 & 1.7 & 2.5 & -18.0 \\
\hline D0-a6 & S1 P929 & 5.3 & 8.7 & 4.0 & 6.0 & 1.6 & 2.0 & -11.0 \\
\hline D0-c4 & S1 P381 & 5.9 & 8.9 & 3.0 & 5.9 & 1.5 & 2.9 & -14.0 \\
\hline D0-a23 & S2 P198 & 2.6 & 8.4 & 4.1 & 7.7 & 3.2 & 3.6 & -20.0 \\
\hline D0-c1 & S2 P642 & 4.9 & 9.0 & 3.7 & 5.8 & 1.8 & 2.1 & -15.0 \\
\hline D0-c2 & S2 P211 & 2.1 & 8.3 & 2.3 & 8.5 & 4.0 & 6.2 & -26.0 \\
\hline D0-c10 & S2 P137 & 2.0 & 8.3 & 1.6 & 13.0 & 4.2 & 11.4 & -29.0 \\
\hline D1-d3 & S2 P141 & 1.9 & 8.0 & 3.1 & 16.4 & 4.2 & 13.3 & -35.0 \\
\hline D2-d2 & S2 P146 & 2.3 & 8.3 & 1.0 & 12.0 & 3.6 & 11.0 & -23.0 \\
\hline D3-b15 & S2 P161 & 4.1 & 8.7 & 2.9 & 5.2 & 2.1 & 2.3 & -14.0 \\
\hline D3-b11 & S2 P335 & 2.8 & 8.6 & 2.2 & 6.0 & 3.1 & 3.8 & -21.0 \\
\hline
\end{tabular}



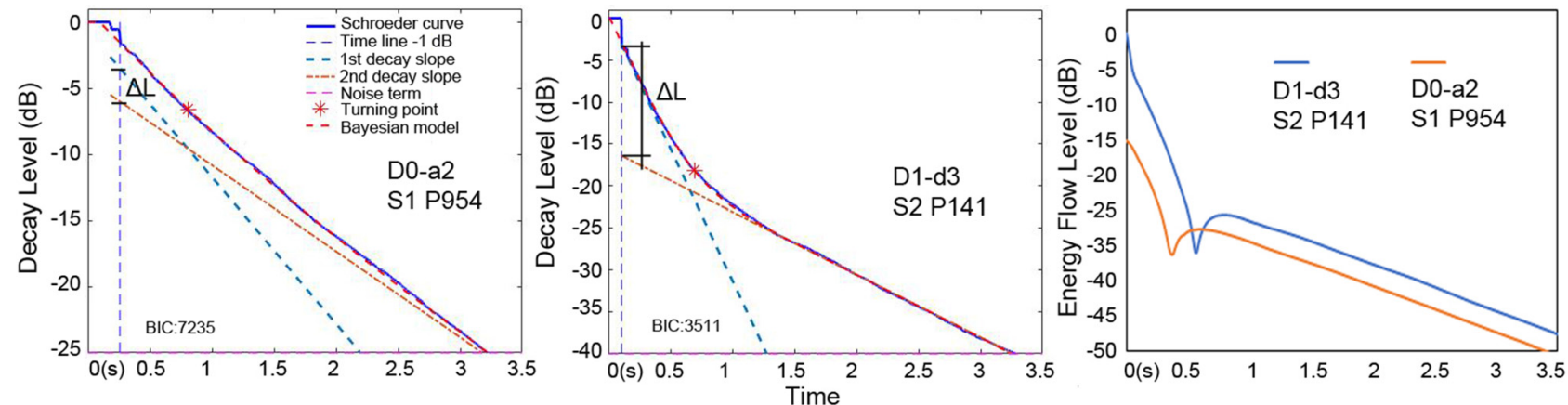

FIG. 7. (Color online) Sound energy decays of data obtained from Ray-t (close-up views, right and center) and sound energy flow decays obtained by DEM (close-up view, right) for D0-a2 S1 P954 and D1-d3 S2 P141; for 1 Khz.

wavelength of $250 \mathrm{~Hz}$ is much smaller than the smallest dimensions of the structure. For this reason, it would be possible to discuss different simulation techniques reliably here as well. For this frequency, samples from different domains are selected for both energy flow decays and Bayesian analysis. For the double-slope cases, the energy flow decay patterns at $250 \mathrm{~Hz}$ are very similar to those observed at $1 \mathrm{kHz}$, except that the energy flow dips occur later in time. Figure 8 illustrates the findings for three different sourcereceiver configurations, two of which (Fig. 7, left and center) generate energy flow dips. For the configuration S2$\mathrm{P} 140$, the shift in the energy dip time is $60 \mathrm{~ms}$, from $310 \mathrm{~ms}$ at $1 \mathrm{kHz}$ to $370 \mathrm{~ms}$ at $250 \mathrm{~Hz}$. For this specific position, there is also another, much earlier dip at a higher level for both octaves at around $40 \mathrm{~ms}$. This is not captured by the Ray- $t$ data. As previously indicated for a couple of other locations, this very initial first dip in the energy flow decay (out of two dips in total) may not relate to the exchange of sound energy between coupled domains, but may instead be attributable to the strong energy moving towards the receiver at these close-by locations. After a time, the point from which the strongest energy emanates shifts from the source to another position in the domain close to the source, indicating that the energy flow now points outwards from a different spot as previously discussed in another study (Jing and Xiang, 2008b).

P161, the second receiver point presented in Fig. 8, is in the sub-domain D3-b15, $1.2 \mathrm{~m}$ above the ground and underneath one of the five arches connecting D3-b to D0-a.
Consequently, this point is a typical aperture position at which energy is exchanged. For S2-P161 the shift in the energy dip time is $50 \mathrm{~ms}$, from $420 \mathrm{~ms}$ at $1 \mathrm{kHz}$ to $470 \mathrm{~ms}$ at $250 \mathrm{~Hz}$. The third case shown in Fig. 8, S1-P8, is one of the positions also measured during the field tests which demonstrates a single slope decay. No energy flow dip can be identified using DEM data either for $1 \mathrm{kHz}$ or for $250 \mathrm{~Hz}$ (Fig. 7, right). This outcome is confirmed by the Ray-t results for the same configuration. In this case, the main difference between the two frequencies is that the decay time (T30) is longer for $250 \mathrm{~Hz}$, which is why the flow decay line for $250 \mathrm{~Hz}$ is above that of $1 \mathrm{kHz}$ in the close-up view shown in the figure. For the single-slope cases, in situ test results indicate that the $T 30$ values are about $1.6 \mathrm{~s}$ longer at $250 \mathrm{~Hz}$ than at $1 \mathrm{kHz}$ (see Fig. 9). The difference in the $T 30$ values at these two octave bands also explains the shift in the timing of energy flow dips, occurring during the earliest stages of the flow decays.

\section{Impact of conversion to a mosque}

In this section, it may be instructive to present the average $T 30$ values of the single-slope cases identified in Hagia Sophia for the different octave bands. Figure 9 shows the average values obtained from the field tests, which were conducted when Hagia Sophia was a museum. The single slope source-receiver configurations for both the DEM and Ray-t models are initially tunes in accordance with these results. The figure also shows the $T 30$ values obtained from
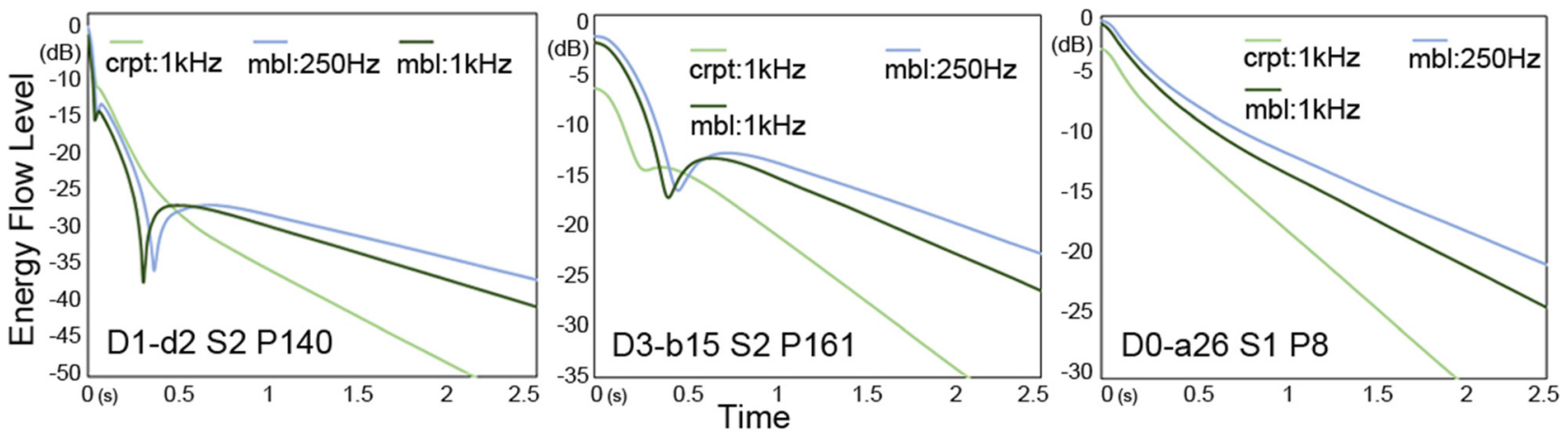

FIG. 8. (Color online) Sample sound energy flow decays from DEM simulations for D1-d2 S2 P140, D3-b15 S2 P161, and D0-a26 S1 P8 for 1 kHz and $250 \mathrm{~Hz}$ for the tested museum state (marble floor) and for $1 \mathrm{kHz}$ for the mosque state (carpeted floor). 


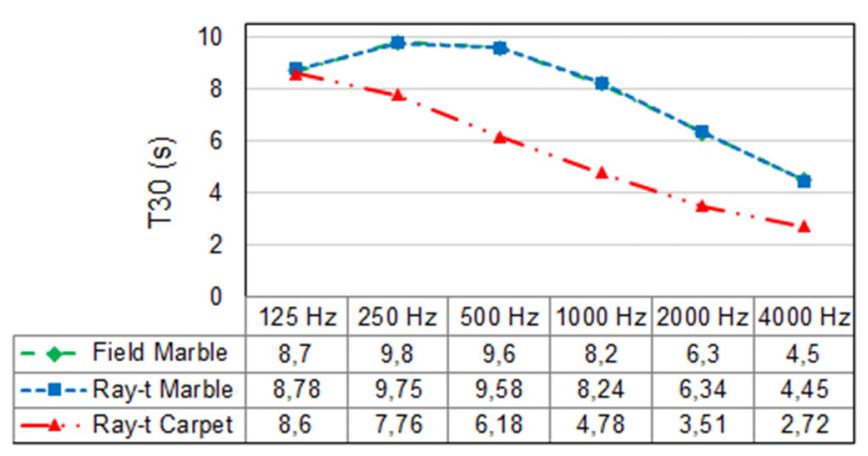

FIG. 9. (Color online) Average T30 values for single-slope sound energy decay cases in the measured state (museum; marble floor) of Hagia Sophia, Ray-t model results tuned by field tests for the measured or museum state (marble floor), and Ray-t model results for the mosque state (carpeted floor).

the Ray-t model for the building in its mosque state (i.e., its condition before it became a museum and its current state following its recent conversion back to a mosque) with a carpeted floor.

The same procedure that was applied for the analysis of energy flow decays in the museum state of the building (with a marble floor) at $250 \mathrm{~Hz}$ was used in the analysis of flow decays in the mosque state (with a carpeted floor). In order to observe the difference made by the absorptive properties of the carpet, the mosque scenario is tested for $1 \mathrm{kHz}$, since for low octave bands the difference between the sound absorption coefficients of marble and carpet gets closer. The analysis is conducted for selected receiver positions located in different domains through both DEM and Ray-t simulations. For the sake of the briefness of the paper, not all the data are presented here. The effect of the use of the Hagia Sophia as a mosque with a carpeted floor can be discussed briefly with reference to Figs. 8 and 9 .

In Fig. 7, the selected source-receiver position configurations used to compare the sound decay at $1 \mathrm{kHz}$ and $250 \mathrm{~Hz}$ for the museum state (with marble floor) of the building are also used to draw comparisons with the sound decay at $1 \mathrm{kHz}$ in the carpeted-floor scenario. Basically, the higher degree of absorption within the structure that stems from the carpeting of the floor causes the energy flow dip either to occur earlier, but with a smaller dip, or to disappear altogether. This indicates that the carpeting of Hagia Sophia contributes to the single-slope sound energy decays and weakens the possibility of multiple-slope cases. It would be more scientific to support this argument with field tests, but this is not likely to be possible so soon after the monument's re-conversion, while it is attracting so much interest and debate.

In Fig. 8, T30 values over octave bands for single-slope sound energy decay cases depict both the mosque scenario as well as the previous museum state of the building (which is very close to the initial church state). It is observed that the sound absorption performance of the carpets does not have much impact on the $T 30$ values at $125 \mathrm{~Hz}$. At higher frequencies, however, the T30 values fall below the values obtained for the museum state. The difference is $2 \mathrm{~s}$ at $250 \mathrm{~Hz}, 3.42 \mathrm{~s}$ at $500 \mathrm{~Hz}$ and $1 \mathrm{kHz}, 2.79 \mathrm{~s}$ at $2 \mathrm{kHz}$, and $1.78 \mathrm{~s}$ at $4 \mathrm{kHz}$. A dryer reverberance, or less liveness, should therefore be expected in the building in its latest condition. Meanwhile, the bass ratio (the ratio of low- to midfrequency reverberation) increases, from $1.03 \mathrm{~s}$ in the museum state to $1.49 \mathrm{~s}$ in the mosque state, pointing to an augmentation of the sensation of the male voice and the warmth of the sound within the building. All these estimates assume that the mosque is empty: the presence of a congregation will change the ratios slightly.

As a final discussion point, this study also investigates how changes in the absorption area and in energy flow dips or multi-slope energy decay patterns are affected either by changes in material or by the frequency range. The quantification of degrees of coupling in relation to architectural parameters is always difficult because it involves many variables. As proposed by Cremer and Muller (1978) and more recently discussed by Billon et al. (2006), the MCF, with a value of between 0 and 1 , denotes the strength of coupling of different volumes through a specific aperture (or apertures), which is applied in statistical theory. The MCF increases as the aperture sizes increase and it also takes the absorption areas of the individual volumes into account. A high coupling factor indicates that the connected volumes behave more like a single space than like an acoustically fragmented complex. The MCF is utilized in an earlier study of Hagia Sophia and of another monument (Sü Gül et al., 2019) to compare single versus multi-domain DEM solutions, and to determine in which conditions the domains should be considered as separate volumes and should be attained by their specific diffusion coefficients.

As shown in Table VI, MCFs are ascertained for domains of Hagia Sophia-including D0, D1, D2, D3, D4, and D5-which are considered to be coupled to the main (whole) volume. In most cases, the different domains are connected by multiple arches, so the total area of these apertures (arches) is used in the estimation of MCFs. In Table VI, the results are presented for different material states (marble floor versus carpeted floor) and different octaves $(1 \mathrm{kHz}$ and $250 \mathrm{~Hz})$. It is observed that the MCF decreases as the absorption area increases (carpeted floor at $1 \mathrm{kHz}$ versus marble floor at $1 \mathrm{kHz}$ and $250 \mathrm{~Hz}$ ). The lowest MCF values are observed in the domain D5, the outer narthex, which is the domain farthest from the sound sources and the apse, and for the carpeted floor state of the building. At the same

TABLE VI. MCF for couplings of different domains $(D)$ to the main volume based on the total coupling aperture areas (total area of arches) and the absorption areas of individual domains $(D)$ at $1 \mathrm{kHz}$ and $250 \mathrm{~Hz}$ for the museum state (marble floor) and $1 \mathrm{kHz}$ for the mosque state (carpeted floor).

\begin{tabular}{lccc}
\hline \hline $\begin{array}{l}\text { \# Domain- main } \\
\text { volume }\end{array}$ & $\begin{array}{c}\text { Marble floor: } \\
1 \mathrm{kHz}\end{array}$ & $\begin{array}{c}\text { Marble floor: } \\
250 \mathrm{~Hz}\end{array}$ & $\begin{array}{c}\text { Carpet floor: } \\
1 \mathrm{kHz}\end{array}$ \\
\hline D0-D & 0.51 & 0.56 & 0.39 \\
D1-D & 0.20 & 0.23 & 0.14 \\
D2-D & 0.17 & 0.19 & 0.12 \\
D3-D & 0.25 & 0.29 & 0.18 \\
D4-D & 0.20 & 0.23 & 0.14 \\
D5-D & 0.13 & 0.15 & 0.08 \\
\hline \hline
\end{tabular}


time, the mosque scenario with a carpeted floor has already been shown to produce shallower energy flow dips and more single-slope cases, while all D5 receiver positions show single-slope patterns only as well. So, the lowest coupling factor does not always indicate the greatest potential for non-exponential energy decay formation as might be expected in a simple two room-coupled scenario.

To sum up, in the light of the source and receiver position configurations that yield double-slope patterns given in Fig. 6, it is clear that the coupling factor alone does not determine the occurrence of multi-slope patterns in structures like Hagia Sophia that have many numbers of domains/volumes coupled to each other. In fact, the distance between the source and the receiver is found to be of greater significance. According to the simulations, the potential for sound energy flow dips supported by double-slope sound energy decays exists only within a maximum horizontal distance of around $45 \mathrm{~m}$ (for the side aisle), and a maximum vertical distance of around $40 \mathrm{~m}$ (for the central domain), of the sound sources, where the plan of Hagia Sophia has a longitudinal axis of $97 \mathrm{~m}$ and the dome reaches to a height of $56 \mathrm{~m}$. Beyond the zones mentioned, the reverberant sound follows an exponential decay (single slope) out of Ray-t data and the sound energy flow decays obtained from the DEM simulations are smooth (convex) and indicate no particular dips.

\section{CONCLUSION}

In this study, Hagia Sophia, one of the world's most significant architectural inheritances, is thoroughly investigated in order to understand the acoustics of its multiple connected spaces. The objective is not only to determine the sound energy decays or sound energy flow decays that occur in the different states of use of the building, but also to utilize its rich architectural scheme to provide a systematic perspective on the study of room acoustics coupling. To this end, 980 receiver positions are distributed inside the whole volume, and simulations are run for two different source positions. The models are initially tuned using data from in situ tests previously conducted for a limited number of positions. The diffusion model is utilized to gather energy flow decays and to observe energy flow dips. Later, the findings are supported by Ray-t simulations, the impulse responses of which are analyzed within a Bayesian framework to estimate the energy decay parameters.

Among the many outputs, it should be pointed out that Hagia Sophia is a system of coupled volumes in which the acoustic conditions vary significantly with the positions of the sources and receivers, just as they do in some other sacred spaces that incorporate such coupled systems (Martellotta et al., 2018). Sound energy flow dips occur in particular zones within a certain distance of the sound sources. This distance can be as far as $45 \mathrm{~m}$ and four sub-domains apart (for the side aisle) on the horizontal plane and $42 \mathrm{~m}$ in a vertical direction for the largest sub-domain, which is under the central dome. Receiver positions in the locations farthest from the sound sources, including the balcony levels, the inner and outer narthex, and the farther side of the space below the central dome towards the narthex, generally yield no flow dips and show a perfectly single slope when the data is analyzed through Ray- $t$ and Bayesian analysis. This indicates a convergence of the early decay towards the late decay (s) as the distance from source to receiver increases, which is also observed in other worship buildings (Cirillo and Martellotta, 2005).

To check the variations in the coupling quantifiers obtained by different simulation techniques, the flow decay dip times and flow dip levels obtained using DEM are compared to the turning point times, DR and $\Delta L$, from the Ray-t results. In almost all of the cases where the sound energy flow decay is convex and no dip is observed using DEM, the Ray-t data also indicate a single-slope sound energy decay. In the cases where multi-slope decays are observed, consistent shifts are detected in the flow dip times and turning point times. Moreover, the magnitudes of $\Delta \mathrm{L}$ (obtained by Ray-t) for different sourcereceiver configurations show a similar pattern to the magnitudes of the sound energy flow dip levels (obtained using DEM) for the same configurations. Thus, the DEM and Ray-t methods provide a consistent overall assessment of the acoustic coupling among the various domains of the interior volume of Hagia Sophia. Meanwhile, the level and sharpness of the energy flow dips observed are shown to be a significant indicator of the strength of the room acoustics couplings at a particular position. Overall, the dips are stronger for the receiver positions close to $\mathrm{S} 2$, a source which is located in a comparatively small sub-domain (with lower reverberation), as in a typical coupled-room scenario. Unlike in some simple two-room coupled spaces (Jing and Xiang, 2008b), there are no particular changes in energy decay patterns at the apertures within Hagia Sophia's fragmented interior, which has multiple apertures in the form of arches. This may be due to the size of the arches: the minimum width of the arches connecting the side aisles to the main volume is $3 \mathrm{~m}$, and the minimum surface area of the aperture is $42 \mathrm{~m}^{2}$. However, some receiver positions without a direct sight-line to the sound source (i.e., in the shadow zone), but which still fall into the zone within a critical distance of the sound sources in which multi-slope decay patterns occur, generate the deepest and most distinctive energy flow dips. The critical distance may vary in different structures according to their sizes, material distributions, and volumetric configuration; however, it may be stated that the for receiver positions that are located three sub-domains farther away from the source position, the potential of multi-slope energy decay formation drops substantially. This applies for both horizontal and vertical adjacencies. On the other hand, it is recommended to locate at least one source in a central axis of a symmetric structure and one other at an off-axis position. Additional source positions, located at smaller domains and close-by receivers within the same domain, will increase the possible number and level of multi-slope sound energy decays.

The study also investigates the effects of variations in frequency and changes in materials and sound absorption. For single-slope cases, reverberation times for the entire volume are longer at $250 \mathrm{~Hz}$ than at $1 \mathrm{kHz}$. In cases with energy flow dips, a similar pattern is observed, and the dips are shifted later in time at $250 \mathrm{~Hz}$. The effect of the use of 
carpeting when the building is used as a mosque-which represents its most recent state-is tested for $1 \mathrm{kHz}$. In carpeted conditions, the flow dips occur earlier and are shallower in some cases, which means that the turning point also occurs at an earlier instant. This implies a weaker degree of coupling, as also previously discussed by Luizard et al. (2014) with reference to the sound energy decays. In general, indeed, the incidence of single-slope cases increases under carpeted conditions. This means that the introduction of carpeting in the architectural scheme of Hagia Sophia may reduce the potential for multislope formation. Meanwhile, when the T30 values of the single-slope cases are estimated through the Ray-t models for different octave bands and for the mosque state, a substantial increase in the bass ratio is observed by comparison with the previous church and museum states, indicating an augmentation in the male voice and increase of warmth of the sound.

To sum up, this study has provided a methodology for investigating room acoustic couplings which involves the examination of sound energy flow dips using DEM followed by Bayesian analysis of Ray-t data. This methodology can be applied to other researches on coupled spaces, in which in situ or scale-model tests may not always be practical or possible. The techniques used in this study also exhibit some shortfalls. For instance, in the field tests at few source-receiver position configurations and specific octave bands triple-slope decay patterns are identified, whereas neither of the simulation techniques has detected such a formation. This could be caused by the early reflection pattern, due to the existence of nearby surfaces that might be missed in the models, or it may be attributable to some repetitive, late-arriving reflections (i.e., flutter echo) from focusing geometries. Such effects might be better understood by means of directional intensity measurements, which have been used in other studies (Martellotta et al., 2018). This may be considered as a topic for future research. Finally, it should be noted that the degree of coupling and the parameters obtained both from DEM and through Bayesian analysis of Ray-t data, as well as the comparisons between them, are through objective parameters. The degree to which multi-slope sound energy decays are perceived and the preferences of users regarding different and varying activity patterns in such sacred spaces is a noteworthy research question for another future study with a focus on subjective testing and analysis.

\section{ACKNOWLEDGMENTS}

The author would like to express her gratitude for the permissions granted by the Ministry of Culture and Tourism and the General Directorate of Turkish Cultural Heritage and Museums for the conduct of the earlier field tests in Hagia Sophia. Special thanks are also extended to Professor Ning Xiang and to Professor Mehmet Çalışkan for their part in motivating this study from the very beginning.

\section{APPENDIX}

In this appendix, the individual domain numbers and receiver positions are coded. D (0 to 9 ) - (a to d) indicate the main domain numbers, and L1-L12 refer to different
ำㅇำ ำ

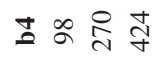

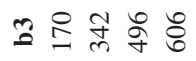

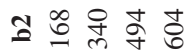

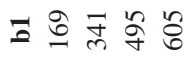

읭 적

สิ

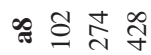

ज氙

ษั

용 융

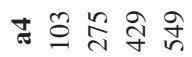

๘

ส

ส 苍只学品

고곡

च产 함

ํํㅇ के

తి

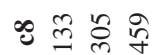

ธิ ڤે

苍嵒

ఆ

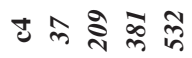

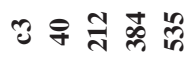

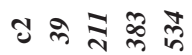

ப

芆守

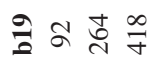

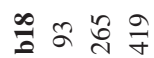

형 石

능 ล웡

늘 $\neq \frac{0}{N}$

빙 유워ำ

3웡

고ำ $\underset{7}{\frac{1}{4}}$

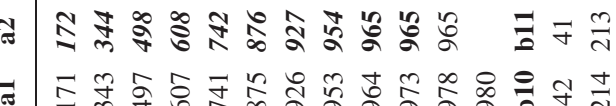

จำง 
$\begin{array}{lllllllllllllllll}\mathrm{L} 2 & 272 & 273 & 217 & 218 & 299 & 300 & 301 & 302 & 304 & 314 & 312 & 313 & 315 & 311 & 303\end{array}$ 
elevations ( $\mathrm{L} 1=1.20 \mathrm{~m}$ above ground; $\mathrm{L} 2=4.20 \mathrm{~m}$ above ground, and so on). The double slope indicating receiver positions for S1 only (boldface fonts), for S2 only (italic fonts) and for both source positions (boldface-italic fonts) are highlighted.

Abdelazeez, K., Hammad, R. N., and Mustafa, A. A. (1991). "Acoustics of King Abdullah Mosque,” J. Acoust. Soc. Am. 90, 1441-1445.

Abdou, A. A. (2003). "Measurement of acoustical characteristics of mosques in Saudi Arabia," J. Acoust. Soc. Am. 113, 1505-1517.

Abel, J. S., Bryan, N. J., Huang, P. P., Kolar, M. A., and Pentcheva, B. V. (2010). "Estimating room impulse responses from recorded balloon pops," in Proceedings of the 129th Convention of AES, November 4-7, San Francisco, CA.

Abel, J. S., Woszczyk, W., Ko, D., Levine, S., Hong, J., Skare, T., Wilson, M. J., Coffin, S., and Lopez-Lezcano, F. (2013). "Recreation of the acoustics of Hagia Sophia in Stanford's Bing Concert Hall for the concert performance and recording of Cappella Romana," in International Symposium on Room Acoustics, June 9-11, Toronto, Canada.

Alonso, A., Suárez, R., and Sendra, J. J. (2018). "On the assessment of the multiplicity of spaces in the acoustic environment of cathedrals: The case of the cathedral of Seville," Appl. Acoust. 141, 54-63.

Alvarez-Morales, L., Giron, S., Galindo, M., and Zamarreno, T. (2016). "Acoustic environment of Andalusian cathedrals," Build. Environ. 103, 182-192.

Anderson, J. S., and Anderson, M. B. (2000). "Acoustic coupling effects in St Paul's Cathedral, London,” J. Sound Vib. 236, 209-225.

Billon, A., Valeau, V., Sakout, A., and Picaut, J. (2006). "On the use of a diffusion model for acoustically coupled rooms," J. Acoust. Soc. Am. 120, 2043-2054.

CAHRISMA Project (2001). "Conservation of the acoustical heritage by the revival and identification of Sinan's Mosques' acoustics," Project No. ICA3-CT-1999-00007, Work package 2, Deliverables (Yıldız Technical University, İstanbul).

Chu, Y., and Maka, C. M. (2009). "Early energy decays in two churches in Hong Kong,” Appl. Acoust. 70, 579-587.

Cirillo, E., and Martellotta, F. (2005). "Sound propagation and energy relations in churches," J. Acoust. Soc. Am. 118, 232-248.

Cremer, L., and Muller, H. A. (1978). "Coupled Rooms," in Principles and Applications of Room Acoustics, Vol. 1 (Elsevier, London), pp. 261-292.

D'Orazio, D., Fratoni, G., Rossi, E., and Garai, M. G. (2020).

"Understanding the acoustics of St. John's Baptistery in Pisa through a virtual approach,” J. Build. Perform. Simul. 13, 320-333.

Eyring, C. F. (1931). "Reverberation time measurements in coupled rooms," J. Acoust. Soc. Am. 3, 181-206.

Giron, S., Alvarez-Morales, L., and Zamarreno, T. (2017). "Church acoustics: A state-of-the-art review after several decades of research,” J. Sound Vib. 411, 378-408.

Harris, C. M., and Feshbach, H. (1950). "On the acoustics of coupled rooms," J. Acoust. Soc. Am. 22, 572-578.

ISO (2009). ISO 3382-1, Acoustics-Measurement of Reverberation Time of Rooms with Reference to other Acoustical Parameters (ISO, Geneva, Switzerland).

Jasa, T., and Xiang, N. (2009). "Efficient estimation of decay parameters in acoustically coupled-spaces using slice sampling," J. Acoust. Soc. Am. 126, 1269-1279.

Jasa, T., and Xiang, N. (2012). "Nested sampling applied in Bayesian room-acoustics decay analysis," J. Acoust. Soc. Am. 132, 3251-3262.

Jing, Y., and Xiang, N. (2008a). "On boundary conditions for the diffusion equation in room acoustic prediction: Theory, simulations, and experiments," J. Acoust. Soc. Am. 123, 145-153.

Jing, Y., and Xiang, N. (2008b). "Visualizations of sound energy across coupled rooms using a diffusion equation model," J. Acoust. Soc. Am. 124, EL360-EL365.

Kahler, H., and Mango, C. (1967). Hagia Sophia. (Frederick A. Praeger, New York).

Kleiner, M., Klepper, D. L., and Torres, R. R. (2010). Worship Space Acoustics. (J. Ross Publishing, Fort Lauderdale, FL).
Luigi, E., and Martellotta, F. (2015). "Acoustics as a cultural heritage: The case of Orthodox churches and of the Russian church in Bari," J. Cult. Heritage 16, 912-917.

Luizard, P., Katz, B. F. G., and Guastavino, C. (2015). "Perceptual thresholds for realistic double-slope decay reverberation in large coupled spaces," J. Acoust. Soc. Am. 137, 75-84.

Luizard, P., Polack, J. D., and Katz, B. F. G. (2014). "Sound energy decay in coupled spaces using a parametric analytical solution of a diffusion equation," J. Acoust. Soc. Am. 135, 2765-2776.

Magrini, A., and Magnani, L. (2005). "Models of the influence of coupled spaces in Christian churches," Build. Acoust. 12, 115-139.

Mark, R., and Çakmak, A.Ş. (1992). Hagia Sophia: From the Age of Justinian to the Present. (Cambridge University Press, Cambridge, UK).

Martellotta, F. (2009). "Identifying acoustical coupling by measurements and prediction-models for St. Peter's Basilica in Rome," J. Acoust. Soc. Am. 126, 1175-1186.

Martellotta, F. (2016). "Understanding the acoustics of Papal basilicas in Rome by means of a coupled-volumes approach," J. Sound Vib. 382, 413-427.

Martellotta, F., Alvarez-Morales, L., Giron, S., and Zamarreno, T. (2018). "An investigation of multi-rate sound decay under strongly non-diffuse conditions: The Crypt of the Cathedral of Cadiz," J. Sound Vib. 421, 261-274.

Meissner, M. (2007). "Computational studies of steady-state sound field and reverberant sound decay in a system of two coupled rooms," Open Phys. 5, 293-312.

Meissner, M. (2012). "Acoustic energy density distribution and sound intensity vector field inside coupled spaces," J. Acoust. Soc. Am. 132, 228-238.

Navarro, J. M., Jacobsen, F., Escolano, J., and Lopez, J. J. (2010). “A theoretical approach to room acoustic simulations based on a radiative transfer model," Acta Acust. united Ac. 96, 1078-1089.

Naylor, G. M. (1993). "ODEON-another hybrid room acoustical model," Appl. Acoust. 38, 131-143.

Nijs, L., Jansens, G., Vermeir, G., and Voorden, M. (2002). "Absorbing surfaces in ray-tracing programs for coupled spaces,” Appl. Acoust. 63, 611-626.

Ollendorff, F. (1969). "Statistical room-acoustics as a problem of diffusion: A proposal," Acta Acust. 21(4), 236-245.

Oyhon, E., and Etingü, B. (1999). Hagia Sophia, Church of Divine Wisdom. Churches in Istanbul. (YKY, İstanbul), pp. 39-41.

Pedrero, A., Ruiz, R., Díaz-Chyla, A., and Díaz, C. (2014). "Acoustical study of Toledo Cathedral according to its liturgical uses," Appl. Acoust. 85, 23-33.

Pentcheva, B. V. (2011). "Hagia Sophia and Multisensory Aesthetics," Gesta ICMA 50, 93-111.

Picaut, J., Simon, L., and Polack, J. D. (1997). “A mathematical model of diffuse sound field based on a diffusion equation," Acta Acust. 83(4), 614-621.

Pu, H., Qiu, X., and Wang, J. (2011). "Different sound decay patterns and energy feedback in coupled volumes," J. Acoust. Soc. Am. 129, 1972-1980.

Raes, C., and Sacerdote, G. G. (1953). "Measurements of the acoustical properties of two Roman basilicas," J. Acoust. Soc. Am. 25, 954-961.

Suárez, R., Alonso, A., and Sendra, J. J. (2015). "Intangible cultural heritage: The sound of the Romanesque Cathedral of Santiago de Compostela," J. Cult. Herit. 16, 239-243.

Suárez, R., Alonso, A., and Sendra, J. J. (2018). "Virtual acoustic environment reconstruction of the hypostyle mosque of Cordoba," Appl. Acoust. 140, 214-224.

Suárez, R., Sendra, J. J., Navarro, J., and León, A. L. (2005). "The sound of the cathedral-mosque of Córdoba," J. Cult. Herit. 6, 307-312.

Summers, E., Torres, R. R., and Shimizu, Y. (2004). "Statistical-acoustics models of energy decay in systems of coupled rooms and their relation to geometrical acoustics," J. Acoust. Soc. Am. 116, 958-969.

Summers, J. E., Torres, R. R., Shimizu, Y., and Dalenback, B. L. (2005). "Adapting a randomized beam-axis tracing algorithm to modeling of coupled rooms via late-part ray tracing," J. Acoust. Soc. Am. 118, $1491-1502$.

Sü, Z., and Xiang, N. (2006). "Further investigations on acoustically coupled spaces using scale-model technique," in Fourth Joint Meeting of 
Acoustical Society of America and Acoustical Society of Japan, Honolulu, Hawaii, USA, 28 November-2 December 2006.

Sü, Z., and Yllmazer, S. (2008). "The acoustical characteristics of the Kocatepe Mosque in Ankara, Turkey," Arch. Sci. Rev. 51, 21-30.

Sü Gül, Z. (2019). "Acoustical Impact of Architectonics and Material Features in the Lifespan of Two Monumental Sacred Structures," J. Acoust. 1.3, 493-516.

Sü Gül, Z., and Çalışkan, M. (2013a). "Acoustical design of Turkish Religious Affairs Mosque," in Proceedings of the 21st International Congress on Acoustics (ICA) Proceedings, June 2-7 Montreal, Canada.

Sü Gül, Z. S., and Çalışkan, M. (2013b). "Impact of design decisions on acoustical comfort parameters: Case study of Dogramacızade Ali Paşa Mosque," App. Acoust. 74, 834-844.

Sü Gül, Z., Çalışkan, M., and Tavukcuoglu, A. (2014). "On the acoustics of Süleymaniye Mosque: From past to present," Megaron. 9, 201-216.

Sü Gül, Z., Çalışkan, M., Tavukcuoglu, A., and Xiang, N. (2018). "Assessment of acoustical indicators in multi-domed historic structures by non-exponential energy decay analysis," Acoust. Aust. 46, 181-192.

Sü Gül, Z., Odabas, E., Xiang, N., and Çalıskan, M. (2019). "Diffusion equation modeling for sound energy flow analysis in multi domain structures," J. Acoust. Soc. Am. 145, 2703-2717.

Sü Gül, Z., Xiang, N., and Çalışkan, M. (2016). "Investigations on sound energy decays and flows in a monumental mosque," J. Acoust. Soc. Am. 140, 344-355.

Sü Gül, Z., Xiang, N., and Çalışkan, M. (2017). "Diffusion equation based finite element modeling of a monumental worship space," J. Comput. Acoust. 25(4), 1-16.
Valeau, V., Picaut, J., and Hodgson, M. (2006). "On the use of a diffusion equation for room-acoustic prediction,” J. Acoust. Soc. Am. 119, 1504-1513.

Visentin, C., Prodi, N., Valeau, V., and Picaut, J. (2012). "A numerical investigation of the Fick's law of diffusion in room acoustics," J. Acoust. Soc. Am. 132, 3180-3189.

Weber, A., and Katz, B. F. G. (2019). "Numerical simulation round robin of a coupled volume case: Preliminary results," in Proceedings of the 23rd International Congress on Acoustics (ICA), September 9-13, Aachen, Germany.

Weitze, C. A., Rindel, J. H., Christensen, C. L., and Gade, A. C. (2002). "The acoustical history of Hagia Sophia revived through computer simulation," in Proceedings of the Forum Acusticum, 3rd European Congress on Acoustics, September 16-20, Seville, Spain.

Wester, E. C. N., and Mace, B. R. (1998). "A statistical analysis of acoustical energy flow in two coupled rectangular rooms," Acta Acust. 84(1), 114-121.

Xiang, N., Alamuru, A., Witew, I. B., and Vorlander, M. (2018). "Experimental investigations on sound energy propagation in acoustically coupled volumes using a high-spatial resolution scanning system," JASA Exp. Lett. 143, EL437-EL442.

Xiang, N., Escolano, J., Navarro, J. M., and Jing, Y. (2013). "Investigation on the effect of aperture sizes and receiver positions in coupled rooms," J. Acoust. Soc. Am. 133, 3975-3985.

Xiang, N., Goggans, P. M., Jasa, T., and Robinson, P. (2011). "Bayesian characterization of multiple-slope sound energy decays in coupled volume systems," J. Acoust. Soc. Am. 129, 741-752.

Xiang, N., Jing, Y., and Bockman, A. C. (2009). "Investigation of acoustically coupled enclosures using a diffusion-equation model," J. Acoust. Soc. Am. 126, 1187-1198. 